\title{
Effects of Olig2-Overexpressing Neural Stem Cells and Myelin Basic Protein-Activated T Cells on Recovery from Spinal Cord Injury
}

\author{
Jian-Guo Hu • Lin Shen • Rui Wang • Qi-Yi Wang • \\ Chen Zhang $\cdot$ Jin Xi $\cdot$ Shan-Feng Ma \\ Jian-Sheng Zhou $\cdot$ He-Zuo Lü
}

Published online: 16 December 2011

(C) The American Society for Experimental NeuroTherapeutics, Inc. 2011

\begin{abstract}
Neural stem cell (NSC) transplantation is a major focus of current research for treatment of spinal cord injury (SCI). However, it is very important to promote the survival and differentiation of NSCs into myelinating oligodendrocytes (OLs). In this study, myelin basic protein-activated T (MBP-T) cells were passively immunized to improve the SCI microenvironment. Olig2-overexpressing NSCs were infected with a lentivirus carrying the enhanced green fluorescent protein (GFP) reporter gene to generate Olig2-GFP-NSCs that were transplanted into the injured site to differentiate into OLs. Transferred MBP-T cells infiltrated the injured spinal cord, produced neurotrophic factors, and induced the differentiation of resident microglia and/or infiltrating blood monocytes into an "alternatively activated" anti-inflammatory macrophage phenotype by producing interleukin-13. As a result, the survival of transplanted NSCs increased fivefold in MBP-T cell-transferred rats compared with that of the vehicle-treated control. In addition, the differentiation of MBP-positive OLs increased 12-fold in Olig2-GFP-NSC-transplanted rats compared with that of GFP-NSC-transplanted controls. In the MBP-T cell and Olig2-GFP-NSC combined group, the number of OL-remyelinated axons significantly increased compared with those of all other groups. However, a significant decrease
\end{abstract}

J.-G. Hu $\cdot$ H.-Z. Lü $(\bowtie)$

Central Laboratory,

First Affiliated Hospital of Bengbu Medical College,

Anhui 233004, People's Republic of China

e-mail: jghu.hzlv@yahoo.com

J.-G. Hu $\cdot$ L. Shen $\cdot$ R. Wang $\cdot$ Q.-Y. Wang $\cdot$ C. Zhang $\cdot$ J. Xi $\cdot$

S.-F. Ma $\cdot$ J.-S. Zhou $\cdot$ H.-Z. Lü

Anhui Key Laboratory of Tissue Transplantation,

Bengbu Medical College,

Anhui 233004, People's Republic of China in spinal cord lesion volume and an increase in spared myelin and behavioral recovery were observed in Olig2-NSC- and NSC-transplanted MBP-T cell groups. Collectively, these results suggest that MBP-T cell adoptive immunotherapy combined with NSC transplantation has a synergistic effect on histological and behavioral improvement after traumatic SCI. Although Olig2 overexpression enhances OL differentiation and myelination, the effect on functional recovery may be surpassed by MBP-T cells.

Keywords Spinal cord injury. Passive immunization . Olig2 $\cdot$ Neural stem cells $\cdot$ Transplantation

\section{Introduction}

Neural stem cells (NSCs) can differentiate into neurons, oligodendrocytes (OLs), and astrocytes, and are a promising candidate for cell transplantation to treat spinal cord injury (SCI) [1]. Recently, NSC-based therapy of SCI has been attempted in numerous animal experiments and produced encouraging results [1-4]. However, the studies also found that after transplantation into the injured spinal cord, most NSCs differentiate into astrocytes, but not OLs and neurons $[5,6]$. This default differentiation hinders not only the effectiveness of NSC transplantation, but also remyelination because of increased astrocytes in the injured area [7]. Therefore, it is important to direct differentiation of transplanted NSCs into OLs and neurons, but not astrocytes.

Autoimmunity-induced inflammation has been viewed as an important mediator of secondary damage in the central nervous system (CNS) following injury. However, based on experimental findings in rodents [8-13], Schwartz et 
al. [12] suggested that autoimmunity is a beneficial endogenous response to CNS injury. Recently, we showed that myelin basic protein-activated T (MBP-T) cells infiltrate SCI sites, produce neurotrophic factors, improve the local microenvironment, protect residual myelin and neurons, and promote motor function recovery [14]. Ziv et al. [15] also demonstrated that a combination immune- and stem cellbased therapies result in a synergistic effect on functional recovery after SCI. These results suggest that CNS antigenactivated T-cell adoptive immunotherapy combined with NSC transplantation is a potential treatment of SCI.

Cell differentiation is regulated by various factors such as inherent differentiation potential and interactions between cells and the extracellular microenvironment [16-19]. Following SCI, the local microenvironment of the injured spinal cord is more complex, which includes natural elements of the spinal cord itself, as well as inflammatory cytokines and cytotoxic substances that have been produced in response to the trauma [20-22]. This new microenvironment is detrimental to the survival of transplanted cells and may be the reason for predominant astrocytic differentiation of transplanted NSCs $[5,6]$. It has been demonstrated that 2 members of the basic helix-loop-helix family (namely Olig1 and Olig2) are transcription factors that determine the differentiation of NSCs into OLs and motor neurons [23-25]. In vitro studies have shown that transient expression of Olig1 initiates the differentiation of NSCs into OL progenitor cells (OPCs) [26], and Olig2 overexpression induces NSC differentiation into mature OLs [27]. A recent study demonstrated that transplantation of Olig2-overexpressing human NSCs improves locomotor recovery and enhances myelination of white matter in the rat spinal cord following contusive injury [28]. These results suggest that transplantation of NSCs that have been genetically modified to overexpress Olig2 may promote differentiation of transplanted NSCs into OLs.

Based on previous reports, we hypothesized that a synergistic and therapeutic effect on SCI would be achieved by combining Olig2-overexpressing NSC transplantation and MBP-T-cell adoptive immunotherapy. Therefore, we transplanted Olig2-overexpressing NSCs into the spinal cords of rats that received MBP-T-cell adoptive immunotherapy following SCI to evaluate the synergistic effect on survival and differentiation of transplanted cells, and the histological and behavioral improvement of spinal cord-injured animals.

\section{Materials and Methods}

\section{Animals}

A total of 368 adult female Sprague-Dawley (SD) rats (200$250 \mathrm{~g}$ ) were used in this study. Among them, 6 rats at gestational day 14.5 were used for NSC isolation, 10 rats were immunized with myelin basic protein (MBP) to generate activated $T$ cells for passive immunization, 4 rats only received laminectomy without contusion (Sham-operated control), and the remaining rats received a contusive SCI. All surgical procedures and postoperative animal care were performed in accordance with the Guide for the Care and Use of Laboratory Animals (National Research Council, 1996) and the Guidelines and Policies for Rodent Survival Surgery provided by the Animal Care and Use Committees of Bengbu Medical College.

\section{Culture of Spinal Cord-Derived NSCs}

Spinal cord-derived NSCs were prepared using a method by Fu et al. [29] with some modifications. Briefly, embryonic spinal cords were collected from embryonic day 14.5 SD rat embryos. Cells were isolated by pipetting in Leibovitz's L-15 medium (Gibco, Grand Island, NY). The suspension was then filtered through a $70-\mu \mathrm{m}$ nylon mesh. After washing, cells were seeded at $1 \times 10^{5}$ cells $/ \mathrm{ml}$ and incubated at $37^{\circ} \mathrm{C}$ in a humidified atmosphere with $5 \% \mathrm{CO}_{2}$. NSC basal medium consisted of Dulbecco's Modified Eagle's Medium (DMEM)/ F12 (Gibco), 1\% $\mathrm{N}_{2}$ and 1\% B27 supplements (Gibco), $3 \mu \mathrm{g} / \mathrm{ml}$ heparin (Sigma, St. Louis, MO), $2 \mathrm{mM}$ glutamine (Gibco), $20 \mathrm{ng} / \mathrm{ml}$ basic fibroblast growth factor (bFGF) (Gibco), and $20 \mathrm{ng} / \mathrm{ml}$ epidermal growth factor (EGF) (Sigma). At days 3 to 4, one-sixth of the NSC basal medium was exchanged. At day 6, neurospheres were collected, mechanically dispersed into single cells, and then re-seeded.

\section{Lentiviral Vector Production, Concentration, and Infection}

Recombinant lentiviral vectors pLenti6.3-EGFP carrying the EGFP reporter gene and pLenti6.3-Olig2-EGFP carrying rat Olig2 and EGFP genes were produced by cloning using a pLenti6.3/v5 DEST lentiviral vector (Invitrogen). To generate high-titer virus, human embryonic $293 \mathrm{~T}$ cells were seeded at $6 \times 10^{6}$ cells $/ 10-\mathrm{cm}$ dish in DMEM and cultured for $16 \mathrm{~h}$. pLenti6.3-EGFP and pLenti6.3-Olig2-EGFP, together with packaging plasmids, $\mathrm{pLP} 1, \mathrm{pLP} 2$, and $\mathrm{pLP} / \mathrm{VSVG}$ (Invitrogen), were cotransfected into $293 \mathrm{~T}$ cells using lipofectamine 2000 according to the manufacturer's instructions (Invitrogen). After $48 \mathrm{~h}$, cell culture supernatant was collected and the lentivirus was concentrated from the medium using ultracentrifugation, followed by ultrafiltration as described elsewhere [30]. For lentiviral vector transfection, fourthpassage neurospheres were dissociated into single cells, suspension was cultured in growth medium for $24 \mathrm{~h}$ and then exposed to pLenti6.3-EGFP and pLenti6.3-Olig2-EGFP lentivirus with a multiplicity of infection of 15 . Medium was replaced with fresh medium after $24 \mathrm{~h}$. After transfection for $48 \mathrm{~h}$, transfection efficiency was estimated by evaluation of EGFP expression using fluorescence microscopy. After 5 days, neurospheres were passaged and fresh 
medium containing blasticidin $(5 \mu \mathrm{g} / \mathrm{ml})$ was added to select for stably transfected cells. Lentivirus-infected NSCs under proliferation and differentiation conditions were subjected to immunocytochemistry to identify cell types. pLenti6.3EGFP- and pLenti6.3-Olig2-EGFP-transfected NSCs were named GFP-NSCs and GFP-Olig2-NSCs, respectively.

\section{Western Blot Analysis}

Western blotting was used to analyze Olig2 expression in NSCs, GFP-NSCs, and GFP-Olig2-NSCs. Briefly, cells were washed twice in phosphate-buffered saline (PBS) and lysed in RadioImmunoPrecipitation Assay (RIPA) buffer (50 mM Tris$\mathrm{HCl}, 150 \mathrm{mM} \mathrm{NaCl}, 1 \mathrm{mM}$ Na3VO4, $1 \mathrm{mM}$ Ethylenediaminetetraacetic acid (EDTA), $1 \%$ Nonidet P-40 (NP-40), 0.5\% sodium deoxycholate, $0.1 \%$ Sodium dodecyl sulfate (SDS), $100 \mu \mathrm{g} / \mathrm{ml}$ Phenylmethanesulfonyl fluoride (PMSF), $30 \mu \mathrm{l} / \mathrm{ml}$ aprotinin, and $4 \mu \mathrm{g} / \mathrm{ml}$ leupeptin, $\mathrm{pH} 7.5$ ). The supernatant was clarified by centrifugation at $16,000 \mathrm{~g}$ for 10 minutes at $4^{\circ} \mathrm{C}$. Protein concentrations of the lysates were determined using a Bicinchoninic acid (BCA) protein assay kit (Pierce, Rockford, IL). For Western blotting, supernatants were diluted in sample buffer (62.5 mM Tris-HCl, pH 6.8, 2\% SDS, 10\% glycerol, $50 \mathrm{mM}$ Dithiothreitol (DTT), and $0.1 \%$ bromophenol blue) and boiled for 5 minutes. Equal amounts of protein $(20 \mu \mathrm{g})$ were resolved by $12 \%$ SDS polyacrylamide gel electrophoresis and then transferred onto Polyvinylidene Fluoride (PVDF) membranes. The membranes were blocked with $5 \%(\mathrm{w} / \mathrm{v})$ skim milk powder in Tris-buffered saline (TBS) with $0.1 \%$ Tween-20 (TBS-T) at room temperature (RT) for 1 $\mathrm{h}$, rinsed in TBS-T and incubated with primary antibodies at $4^{\circ} \mathrm{C}$ overnight. Primary antibodies used were mouse anti- $\beta$ actin (1:5000; Santa Cruz Biotechnology) and rabbit antiOlig2 (1:1000; Chemicon, Temecula, CA). After rinsing with TBS-T, membranes were incubated with appropriate horseradish peroxidase-conjugated secondary antibodies (KPL, Gaithersburg, MD) at RT for $1 \mathrm{~h}$. To visualize immunoreactive proteins, an ECL kit (Pierce) was used following the manufacturer's instructions.

\section{NSC Differentiation}

To induce NSC differentiation, dissociated cells were seeded onto $200 \mu \mathrm{g} / \mathrm{ml}$ poly-L-lysine-coated coverslips at $5 \times 10^{4}$ cells/ coverslip. Then, growth factors were removed from the growth medium and $1 \%$ fetal bovine serum (FBS) (Gibco) was added (referred to as NSC differentiation medium). Cells were differentiated for 7 days and then fixed for immunostaining.

\section{Immunocytochemistry}

For NSCs, free-floating neurospheres were fixed in $4 \%$ paraformaldehyde (PFA) (Sigma) at $4^{\circ} \mathrm{C}$ overnight, PBS washed, and cryoprotected in PBS containing 30\% sucrose. Neurospheres were embedded in OCT (Sakura FineTec Inc., Torrance, CA) and sectioned with a cryostat. For differentiated NSCs, cells were fixed with $4 \%$ PFA in PBS (0.01 M, pH 7.4) for 10 minutes at RT. Sections of neurospheres and differentiated NSCs were mounted on poly-L-ornithine-coated coverslips and blocked with 10\% normal goat serum (NGS) containing $0.3 \%$ Triton $\mathrm{X}-100$ for $1 \mathrm{~h}$ at RT, and then incubated with mouse anti-rat primary antibodies against nestin $(1: 100$; Pharmingen, San Diego, CA) for NSCs, $\beta$ III-tubulin (1:800; Sigma) for neurons, glial fibrillary acidic protein (GFAP) (1:200; Sigma) for astrocytes, and MBP (1:2000; Chemicon, Temecula, CA) for OLs overnight at $4^{\circ} \mathrm{C}$. Sections were then incubated with rhodamine-conjugated goat anti-rabbit $\operatorname{IgG}$ (1:50; Cappel, Costa Mesa, CA) for $1 \mathrm{~h}$ at $37^{\circ} \mathrm{C}$. Sections were then rinsed and mounted with $\mathrm{Gel} /$ Mount aqueous mounting media (Biomeda Corp., Foster City, CA) containing Hoechst 33342, a nuclear dye $(0.5 \mu \mathrm{M}$; Sigma). Immunostaining was examined with an Olympus BX60 microscope.

\section{Generation of MBP-T Cells and Ovalbumin-Reactive-T Cells}

MBP- and ovalbumin-reactive-T (OVA-T) cells were generated from draining lymph node cells that were obtained from SD rats after immunization with guinea pig MBP (Sigma, St. Louis, MO) and OVA (Sigma) as described elsewhere $[14,31]$. Briefly, the previously described antigens were dissolved in PBS at $1 \mathrm{mg} / \mathrm{ml}$. The proteins were emulsified in an equal volume of incomplete Freund's adjuvant (Bio Basic Inc., East Markham, Ontario, Canada) supplemented with $4 \mathrm{mg} / \mathrm{ml}$ mycobacterium tuberculosis (Bio Basic Inc). Then, $0.2 \mathrm{ml} \mathrm{MBP-} \mathrm{and}$ OVA-containing emulsions were injected into the 2 hind footpads of the rats. Nine days postinjection, the rats were sacrificed, and draining lymph nodes in the inguinal areas were surgically removed and dissociated. Cells were cultured at $1 \times 10^{7}$ cells $/ \mathrm{ml}$ with their immunized antigen $(25 \mu \mathrm{g} / \mathrm{ml})$. Proliferation medium consisting of Roswell Park Memorial Institute (RPMI) 1640 supplemented with L-glutamine $(2 \mathrm{mmol} / \mathrm{L}), 2$-mercaptoethanol $(50 \mu \mathrm{mol} / \mathrm{L})$, sodium pyruvate $(1 \mathrm{mmol} / \mathrm{L})$, gentamycin $(50,000 \mathrm{IU} / \mathrm{L})$, nonessential amino acids, and $2 \%$ autologous rat serum. After $72 \mathrm{~h}$, lymphoblasts were separated by Percoll (Amersham Pharmacia Biotech, Piscataway, NJ) gradient centrifugation and placed in proliferation medium supplemented with $10 \%$ FBS and $10 \%$ medium supernatant from concanavalin A-stimulated spleen cells, which contains T-cell growth factors. After 5 to 7 days, cells were re-stimulated with their immunized antigen $(10 \mu \mathrm{g} / \mathrm{ml})$ using mitomycin-treated splenocytes as antigen-presenting cells [14]. MBP- and OVA-T cells were expanded for at least 3 cycles of propagation and restimulation before transplantation into spinal cord-injured rats. 
The specificities of MBP- and OVA-T cells were confirmed by proliferation in response to their immunized antigen.

\section{Lymphocyte Proliferation Assay}

Lymphocyte proliferation assays were performed in 96 well plates. MBP- and OVA-T cells were seeded at $2 \times$ $10^{5}$ cells/well in $200 \mu \mathrm{l}$ proliferation medium and cocultured with mitomycin-treated splenocytes $\left(2 \times 10^{6}\right.$ cells/ well) and $25 \mu \mathrm{g} / \mathrm{ml} \mathrm{MBP,} 25 \mu \mathrm{g} / \mathrm{ml}$ OVA, $25 \mu \mathrm{g} / \mathrm{ml}$ bovine serum albumin, and $250 \mu \mathrm{g} / \mathrm{ml}$ spinal cord homogenate extract (SCHE) (final concentration) from either rat or guinea pig (rSCHE and gpSCHE, respectively). Cultures were incubated at $37^{\circ} \mathrm{C}$ with $5 \% \mathrm{CO}_{2}$ for $48 \mathrm{~h}$, and then $1 \mu \mathrm{Ci}$ ${ }^{3} \mathrm{H}-\mathrm{TdR}$ was added to each well, followed by $18 \mathrm{~h}$ incubation. Then the cells were harvested and thymidine uptake was assessed by liquid scintillation counting.

Enzyme-Linked Immunosorbent Assays for Cytokine and Neurotrophin Measurements

MBP- and OVA-T cells were cultured for a week in proliferation medium and then PBS washed and re-suspended in stimulation medium. T cells $\left(1 \times 10^{6}\right.$ cells $\left./ \mathrm{ml}\right)$ were incubated with mitomycin-treated splenocytes $\left(2 \times 10^{7}\right.$ cells/ $\mathrm{ml}$ ) in the presence of $25 \mu \mathrm{g} / \mathrm{ml} \mathrm{MBP}, 25 \mu \mathrm{g} / \mathrm{ml} \mathrm{OVA}, 250$ $\mu \mathrm{g} / \mathrm{ml} \mathrm{rSCHE} \mathrm{(final} \mathrm{concentration),} \mathrm{and} \mathrm{without} \mathrm{antigens}$ (PBS alone) in $200 \mu \mathrm{l}$ proliferation medium. After $48 \mathrm{~h}$, the concentrations of interferon- $\gamma$ (IFN- $\gamma$ ), interleukin-4 (IL-4), interleukin-10 (IL-10), interleukin-13 (IL-13), brain-derived neurotrophic factor (BDNF), nerve growth factor (NGF), and neurotrophin-3 (NT-3) in medium supernatants were measured using enzyme-linked immunosorbent assays (ELISAs), according to the manufacturer's instructions. The ELISA kit for IL-13 was purchased from Invitrogen; BDNF, NGF, and NT-3 ELISA kits were purchased from Cell Applications, Inc. (San Diego, CA); and IFN- $\gamma$, IL-4, and L-10 ELISA kits were purchased from R\&D Systems (Minneapolis, MN).

\section{Contusive SCI}

Contusive SCI was performed using a New York University impactor as described elsewhere [14]. Briefly, rats were anesthetized with pentobarbital $(50 \mathrm{mg} / \mathrm{kg}$, intraperitoneally) and received a laminectomy at the $\mathrm{T} 9$ vertebra. After spinous processes of the $\mathrm{T} 7$ and $\mathrm{T} 11$ vertebrae were clamped to stabilize the spine, the exposed dorsal surface of the cord was subjected to a weight drop injury using a $10 \mathrm{~g}$ rod (2.5-mm diameter) dropped at a height of $25 \mathrm{~mm}$. Sham-operated rats only received laminectomy without contusion. After SCI, muscles and skin were closed in layers, and rats were placed in a temperature- and humiditycontrolled chamber. Manual bladder emptying was performed
3 times daily until reflex bladder emptying was established. To prevent infections, animals were daily provided with chloramphenicol $(50 \sim 75 \mathrm{mg} / \mathrm{kg})$ via drinking water.

\section{Passive Immunization}

For passive immunization, rats were intravenously injected with $2 \times 10^{7}$ MBP- or OVA-T cells suspended in $1 \mathrm{ml}$ sterile PBS at $1 \mathrm{~h}$ post-SCI. Rats in the vehicle control group were intravenously injected with $1 \mathrm{ml}$ sterile PBS at $1 \mathrm{~h}$ post-SCI.

\section{RNA Extraction and Real-Time RT-PCR}

mRNA expression was measured by real-time RT-PCR as described elsewhere [32]. Total RNA from injured spinal cords (1-cm spinal cord segment containing the injury epicenter) was extracted using TRI reagent (Molecular Research Center, Cincinnati, OH) according to the manufacturer's instructions. RNA was reverse transcribed into cDNA using a reverse transcription system (Promega, Madison, WI). Real-time PCR was performed on an ABI 7900 PCR detection system (Applied Biosystems, Foster City, CA) using a SYBR Green PCR Master Mix (Applied Biosystems). Parallel amplification of the glyceraldehyde3-phosphate dehydrogenase housekeeping gene was used to normalize gene expression. PCR primer sequences are listed in Table 1. The relative expression level of target mRNA was calculated using the ${ }^{\Delta \Delta} \mathrm{Ct}$ method [33]. All data were expressed as relative to injured spinal cord without T-cell transfer, which was designated as one.

\section{Isolation of Infiltrating Cells}

Cells that infiltrated the spinal cord were isolated as described elsewhere [14, 34] with some modifications. Briefly, at the indicated time periods post-injury, rats were perfused with PBS, and spinal cord segments T8-10 were removed by insufflation and dissociated by gently grinding the tissue into a single-cell suspension that was passed through a $45-\mu \mathrm{m}$ nylon mesh with a syringe plunger. Infiltrating cells were isolated by Percoll gradient centrifugation and re-suspended in staining buffer (PBS containing 5\% FBS and $0.01 \mathrm{M}$ sodium azide) for immunolabeling.

\section{Flow Cytometry}

Phenotypes of MBP- and OVA-T cell, as well as infiltrating cells in the spinal cords were determined using flow cytometry. For immunolabeling, cells were incubated with the following panel of anti-rat monoclonal antibodies: biotinconjugated anti-CD3 (1 $\mu \mathrm{g} / 10^{6}$ cells; eBioscience, San Diego, CA) followed by phycoerythrin (PE)-Cy5-conjugated streptavidin $\left(0.2 \mu \mathrm{g} / 10^{6}\right.$ cells; eBioscience), fluorescein 
Table 1 Real-Time PCR Primers Used in the Study
$\mathrm{BDNF}=$ brain-derived neurotrophic factor; IFN=interferon; IL=interleukin; $\mathrm{NGF}=$ nerve growth factor; NT-3 = neurotrophin-3

\begin{tabular}{llll}
\hline Gene & GenBank Accession No. & Forward Primer 5' - 3' & Reverse Primer 5' - 3' \\
\hline IL-10 & NM_012854.2 & CAGTCAGCCAGACCCACA & GGCAACCCAAGTAACCCT \\
IL-1 $\beta$ & NM_031512.2 & GGCAACTGTCCCTGAACT & TCCACAGCCACAATGAGT \\
IL-13 & NM_053828.1 & AATCCCTGACCAACATCT & ATAAACTGGGCTACTTCG \\
IFN- $\gamma$ & NM_138880.2 & CTGGCAAAAGGACGGTAA & TGTGCTGGATCTGTGGGT \\
IL-4 & NM_201270.1 & ACCCTGTTCTGCTTTCTC & GTTCTCCGTGGTGTTCCT \\
BDNF & NM_012513.3 & TCTGTAATCGCCAAGGTG & ATGCTGGAAGGTAATGTG \\
NT-3 & NM_031073.2 & TGGAAATAGTCATACGGA & CAACTTGATAATGAGGGA \\
NGF & XM_227525.5 & AAGGCTTTGCCAAGGACG & GTGATGTTGCGGGTCTGC \\
\hline
\end{tabular}

isothiocyanate-conjugated anti-CD3 $\left(1 \mu \mathrm{g} / 10^{6}\right.$ cells; Caltag Laboratories, Burlingame, CA), PE-conjugated anti-CD8 (0.5 $\mu \mathrm{g} / 10^{6}$ cells; Caltag Laboratories), allophycocyaninconjugated anti-CD4 (0.2 $\mu \mathrm{g} / 10^{6}$ cells; eBioscience), Alexa Fluor 647-conjugated anti-CD163 (1 $\mu \mathrm{g} / 10^{6}$ cells; AbD Serotech, Oxford, UK), PE-conjugated anti-CD86 (0.2 $\mu \mathrm{g} / 10^{6}$ cells; eBioscience), and biotin-conjugated anti-CD68 mAb (1 $\mu \mathrm{g} / 10^{6}$ cells; AbD Serotech) followed by PE-Cy5conjugated streptavidin $\left(0.2 \mu \mathrm{g} / 10^{6}\right.$ cells $)$. After incubation at $4^{\circ} \mathrm{C}$ for 30 minutes, cells were washed 3 times with staining buffer, fixed with $1 \%$ PFA in PBS, and analyzed using a FACSCalibur flow cytometer (Becton Dickinson, San Diego, CA). Isotype-matched antibodies were used to control for nonspecific staining that was subtracted from specific staining results. A minimum of 10,000 events were collected and analyzed by WinMDI 2.8 software (J. Trotter, The Scripps Research Institute, La Jolla, CA).

\section{Transplantation Procedures}

After 9 days of SCI, 348 rats were divided into 9 groups (Table 2). To transplant NSCs, rats were anesthetized with pentobarbital (50 mg/kg, intraperitoneal), the spinal cord was re-exposed, and a small window was opened in the dura. Four injections were performed left and right laterally 0.6$\mathrm{mm}$ from the midline, 2-mm cranial and caudal to the lesion site, at a depth of $1.1 \mathrm{~mm}$. For cell transplantation, $2-\mu \mathrm{l} \mathrm{NSCs}$ $\left(1 \times 10^{5}\right.$ cells $)$ in NSC medium were injected at $0.5 \mu \mathrm{l} / \mathrm{min}$ into each site through a glass micropipette with a $50 \sim 70 \mu \mathrm{m}$ outer diameter and sharp beveled tip at $30 \sim 50^{\circ}$ as described elsewhere $[18,35]$. The microinjection system was powered by compressed nitrogen, and a total of $4 \times 10^{5}$ cells were transplanted into each rat. Muscle and skin were sutured and normal saline and antibiotics were administered to prevent dehydration and infection. Animals were sacrificed at the indicated time periods post-transplantation.

Immunohistochemical Assay

After the indicated time periods post-transplantation, animals were administered an overdose of sodium pentobarbital (nembutal; $80 \mathrm{mg} / \mathrm{kg}$, interperitoneally) and transcardially exsanguinated with $200 \mathrm{ml}$ physiological saline followed by fixation with $300 \mathrm{ml}$ ice-cold 4\% PFA in 0.01 M PBS (pH 7.4). After perfusion, a 2-cm spinal cord segment containing the injury epicenter was removed, postfixed overnight in 4\% PFA in $0.01 \mathrm{M} \mathrm{PBS}$ (pH 7.4), and transferred to $30 \%$ sucrose in 0.01 M PBS (pH 7.4) at $4^{\circ} \mathrm{C}$ overnight. Then the specimens were cut into segments spaced $5 \mathrm{~mm}$ from the cervical to the sacral cord. Segments were placed in OCT compound embedding medium

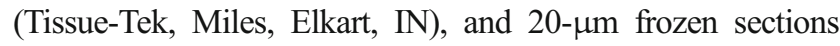
were obtained horizontally and transversely using a cryostat (Leica CM1900, Bannockburn, IL), followed by thaw mounting on poly-L-lysine-coated slides (Sigma). For immunohistochemistry, sections were blocked with $10 \%$ NGS in $0.01 \mathrm{M}$ PBS ( $\mathrm{pH} 7.4$ ) for $1 \mathrm{~h}$, and primary mouse anti-rat antibodies against nestin (1:100; Pharmingen), MBP (1:2000; Chemicon), GFAP (1:200; Sigma), ßIII-tubulin (1:800; Sigma), arginase I (1:100; Santa Cruz), and CD4 (1:100; SeroTec Inc., Raleigh, NC), and rabbit antibodies against CC-chemokine receptor 7 (CCR7) (1:250; Cell Application, San Diego, CA), and neurofilament M (NFM) (1:200; Millipore Bioscience Research Reagents) were applied overnight at $4^{\circ} \mathrm{C}$. The following day, sections were incubated for 60 minutes at $37^{\circ} \mathrm{C}$ with rhodamine-conjugated goat anti-mouse (1:50; Jackson Immuno Research Laboratories, West Grove, PA) and goat anti-rabbit antibodies (1:100; Jackson Immuno Research Laboratories), or amino-methyl-coumarin-acetate-conjugated donkey anti-rabbit Fab' fragments (1:100; Jackson Immuno Research Laboratory). Slides were then washed, coverslipped, and examined using an Olympus BX60 microscope.

For immunocytochemistry and immunohistochemistry, primary anti-serum omission controls and normal mouse and goat serum controls were used to confirm the specificity of immunofluorescence labeling. Cell quantification of spinal cord tissue was performed in an unbiased stereological manner as described elsewhere [2].

Histological Analyses

Eight weeks after SCI, animals were sacrificed as previously described. Histological analyses were performed as 
described elsewhere [14]. Briefly, spinal cords were cut into $10-\mathrm{mm}$ segments and serially sectioned at $20-\mu \mathrm{m}$ thicknesses transversely through the entire injury site. Two sets of serial sections spaced $200 \mu \mathrm{m}$ apart were respectively stained with luxol fast blue (LFB) and neutral red to identify myelinated white matter and residual ventral horn $(\mathrm{VH})$ motoneurons.

Toluidine Blue Staining

Toluidine blue staining was performed as described elsewhere [14]. Briefly, spinal cord segments were fixed overnight in a solution containing $2 \%$ glutaraldehyde and $5 \%$ sucrose in $0.1 \mathrm{M}$ sodium cacodylate buffer, $\mathrm{pH} 7.4$, followed by $1 \%$ osmium tetroxide in the same buffer for $1 \mathrm{~h}$. Tissue was embedded in Spurr's epoxy resin and cured at $70^{\circ} \mathrm{C}$. Transverse semithin sections $(1 \mu \mathrm{m})$ were stained with a mixture of $1 \%$ toluidine blue and $1 \%$ sodium borate. For statistical analysis, the numbers of spared myelin were calculated in 4 random $10 \times 40$-fold microscope views in the middle of the lesion and pial borders in the dorsal, lateral, and ventral columns.

Immuno-Electron Microscopy

For immuno-electron microscopy (immuno-EM), rats were perfused with the same perfusion fixatives as previously described for immunohistochemistry with the addition of $0.1 \%$ glutaraldehyde. After perfusion, spinal cords were excised, postfixed overnight in 4\% PFA and horizontal sections $(40 \mu \mathrm{m})$ were cut using a vibratome. Sections were subjected to immunohistochemical processing for GFP detection using the avidin-biotin peroxidase complex method. Briefly, sections were blocked in $10 \%$ NGS in $0.01 \mathrm{M}$ PBS containing $0.05 \%$ Triton X-100 for 30 minutes at RT and then incubated with a polyclonal rabbit anti-GFP antibody (1:2000; Chemicon) overnight at $4^{\circ} \mathrm{C}$. After several rinses in $0.01 \mathrm{M}$ PBS, sections were incubated with biotinylated goat anti-rabbit $\operatorname{IgG}(1: 200$; Vector Laboratories, Burlingame, CA) for $1 \mathrm{~h}$ and then incubated with Vector avidin-biotin peroxidase complex reagent (1:200; Vector Laboratories) for $1 \mathrm{~h}$ at RT. The reaction product was visualized by 5 minutes of incubation with $0.05 \%$ diaminobenzidine tetrahydrochloride and $0.01 \%$ $\mathrm{H}_{2} \mathrm{O}_{2}$ in $0.05 \mathrm{M}$ Tris- $\mathrm{HCl}$, pH 7.6. Sections were postfixed in $1 \%$ osmium tetroxide for $1 \mathrm{~h}$ at RT, dehydrated in a graded ethanol series and propylene oxide, and flatembedded in Epon on slides. After sectioning, specimens were examined, and the middle of the lesion and pial borders in the dorsal, lateral, and ventral columns were excised and glued to Epon cylinders for ultrathin sectioning. Ultrathin sections were mounted on grids, examined, and photographed using a Philip CM10 electron microscope (Philips, Einhoven, the Netherlands). 
Basso, Beattie, and Bresnahan Locomotor Rating Scale

Behavioral assessments were performed using the Basso, Beattie, and Bresnahan (BBB) locomotor rating scale, a 21 point scale (0-21) based on observations of hind-limb movements of a rat freely moving in an open field [36, 37]. The BBB score was evaluated at 1 and 3 days, then at 1, 2, 3, 4, 5, 6 , and 7 weeks after injury. During the evaluation, animals were allowed to walk freely on the open-field surface for 4 minutes while being observed by 2 blinded scorers.

\section{Statistical Analyses}

BBB scores were analyzed using repeated measures analysis of variance, followed by Tukey's pairwise comparison at each time point. Other data were analyzed using nonparametric Kruskal-Wallis analysis of variance, followed by individual
Mann-Whitney $U$ tests. The relationship between BBB scores and histological outcomes was determined by Pearson correlation coefficients $(r)$. Statistical differences were considered significant at $p<0.05$.

\section{Results}

Isolation, Differentiation, and Identification of NSCs

After dissociated NSCs were plated in growth medium containing EGF and bFGF for 3 to 4 days, single cells proliferated to form small clusters and then larger floating neurospheres. Immunostaining of sectioned neurospheres revealed that the cells were positive for nestin (95.58$98.84 \%$; Fig. $1 \mathrm{~A}_{1}$ ), an intermediate filament protein that is mainly expressed in neural stem cells and precursor cells

A

$(-)$
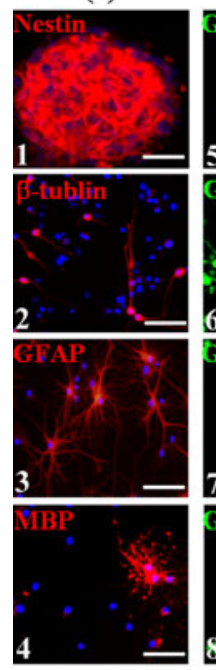

B

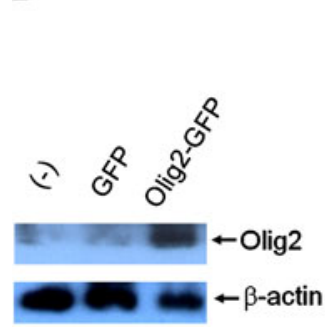

GFP
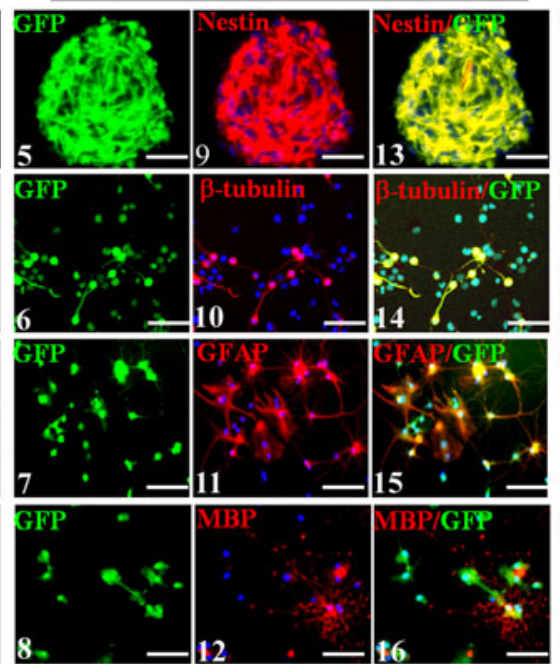

$\mathrm{C}$

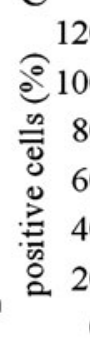

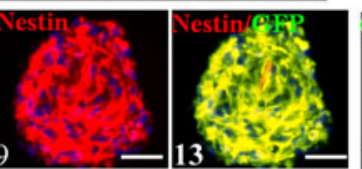

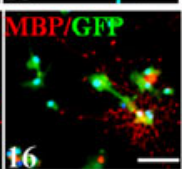

20

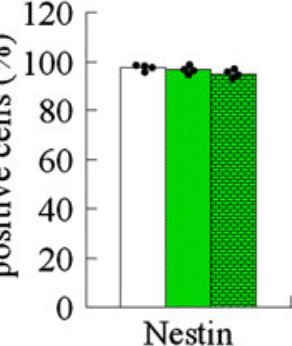

Nestin
Fig. 1 The characteristics of nontransfected, green fluorescent protein (GFP)-transfected, and Olig2-GFP-transfected neural stem cells (NSCs) are shown. The characteristics of nontransfected (-), GFP-transfected (GFP), and Olig2-GFP-transfected (Olig2-GFP) NSCs were identified by immunostaining. (A) All gene-modified NSCs express GFP (green, $\left.\mathrm{A}_{5-8}, 17-20\right)$. Cells in neurosphere sections are immuno-positive for nestin (red, $\mathrm{A}_{1,9}, 21$ ). After culture in NSC differentiation medium for 7 days, NSCs differentiate into neurons ( $\beta$ III-tubulin $\left.{ }^{+}, \mathrm{A}_{2,10,22}\right)$, astrocytes $\left(\mathrm{GFAP}^{+}, \mathrm{A}_{3,11,23}\right)$, and OLs (myelin basic protein $\left.[\mathrm{MBP}]^{+}, \mathrm{A}_{4}, 12,24\right)$. Co-localization of cell

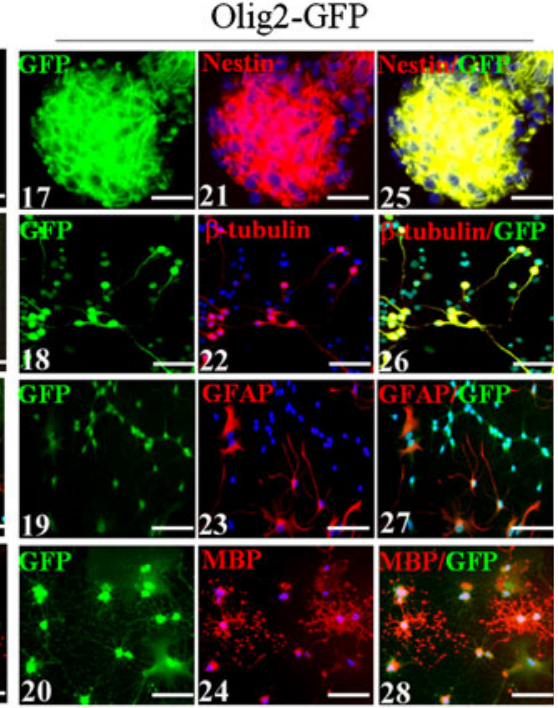

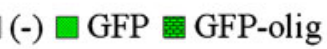

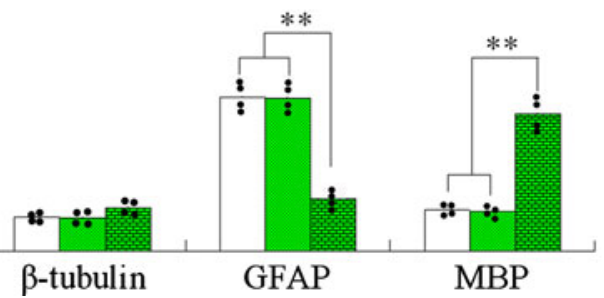

specific markers (red) and GFP (green) in NSCs and their derivatives are shown in overlay images (yellow, $\mathrm{A}_{13-16,25-28}$ ). Cells were counterstained with Hoechst 33342 (blue), a nuclear dye. Scale bars: $25 \mu \mathrm{m}$. (B) Preceding the differentiation experiments, Western blot analysis of Olig2 was performed using cell lysates of the 3 NSC types. (C) Statistical graphs show the proportion of nestin-, ßIII-tubulin-, GFAP- and MBP-positive cells in various groups. Data are median values (histograms) and individual data points (dots); $(\mathrm{n}=4) ; * * p<0.01$ 
[38]. After plating on poly-ornithine-coated coverslips in NSC differentiation medium for 7 days, cells migrated out of the neurospheres and differentiated into a mixture of neurons ( $\beta$ III-tubulin ${ }^{+}, 12.14-14.7 \%$; Fig. $\left.1 \mathrm{~A}_{2}\right)$, astrocytes $\left(\mathrm{GFAP}^{+}, 57.61-66.90 \%\right.$; Fig. $\left.1 \mathrm{~A}_{3}\right)$, and OLs $\left(\mathrm{MBP}^{+}, 14.33-\right.$ 18.85\%; Fig. $1 \mathrm{~A}_{4}$ ).

\section{Effect of Olig2 Overexpression on NSC Differentiation in Vitro}

Preceding the differentiation experiments, Western blot analysis of Olig2 was performed using cell lysates from nontransfected (-), GFP-transfected (GFP), and Olig2GFP-transfected (Olig2-GFP) NSCs. Low Olig2 expression was detected in (-) and GFP-NSCs, whereas Olig2-GFPNSCs expressed high levels of Olig2 (Fig. 1B). These data indicated that lentiviral vector-mediated Olig2 overexpression in NSCs was successful. Next, we compared the characterization of NSCs (-), GFP-NSCs, and Olig2-GFPNSCs. There was no significant difference in neurosphere morphology among the 3 NSC groups (the first column in Fig. 1). Immunostaining of sectioned neurospheres revealed that $>95 \%$ of cells were positive for nestin (Fig. 1 $A_{1}, A_{9}$, $A_{21}$, and Fig. 1C). No significant difference was found in the proportion of nestin-positive cells (Fig. 1C; $p>0.05$ ). After 7 days differentiation, the proportions of neurons $(\sim 15 \%)$, astrocytes $(>60 \%)$, and OLs $(\sim 16 \%)$ showed no significant difference between NSCs $(-)$ and GFP-NSCs (Fig. 1C, $p>0.05$ ). However, more than 50\% (50.8-62.88\%) of Olig2-GFP-NSCs differentiated into fully mature OLs with elaborate myelin extensions that stained positive for MBP (Fig. 1 $\mathrm{A}_{24}$ and $\mathrm{C}$ ), which was significantly higher compared with that of the other groups (Fig. 1C, $p<0.01$ ). The proportion of $\beta$ III-tubulin-positive cells in Olig2-GFPNSCs was also increased (14.51-20.18\%), which was slightly higher compared with that of the other groups (Fig. $1 \mathrm{~A}_{2}, \mathrm{~A}_{10}, \mathrm{~A}_{22}$, and Fig. $1 \mathrm{C} ; p>0.05$ ). Relatively, the proportion of GFAP-positive cells in Olig2-GFP-NSCs decreased (17.81-23.70\%), which was significantly lower compared with that of the other groups (Fig. $1 \mathrm{~A}_{3}, \mathrm{~A}_{11}, \mathrm{~A}_{23}$, and Fig. $1 \mathrm{C} ; p<0.01$ ).

\section{Phenotypes and Specificities of MBP-T Cells}

Prior to T-cell transfer into spinal cord-injured rats, the phenotype of MBP-T cells was identified by flow cytometry. As shown in Fig 2A, MBP-T cells were mainly $\mathrm{CD}^{+} \mathrm{CD}^{+} \mathrm{T}$ cells $(>98 \%)$. The antigen-specific lymphocyte proliferation assay showed that in the presence of $250 \mu \mathrm{g} / \mathrm{ml} \mathrm{rSCHE}$ or gpSCHE, or $25 \mu \mathrm{g} / \mathrm{ml} \mathrm{MBP,}{ }^{3} \mathrm{H}-\mathrm{TdR}$ incorporation was significantly increased in MBP-T cells, but not OVA-T cells. In medium and non-CNS antigen (bovine serum albumin) controls, MBP- and OVA-T cells did not proliferate
A

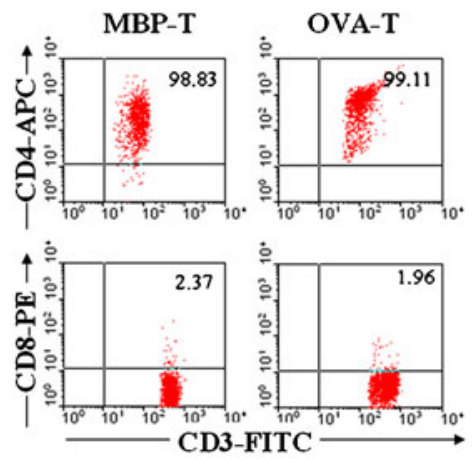

B

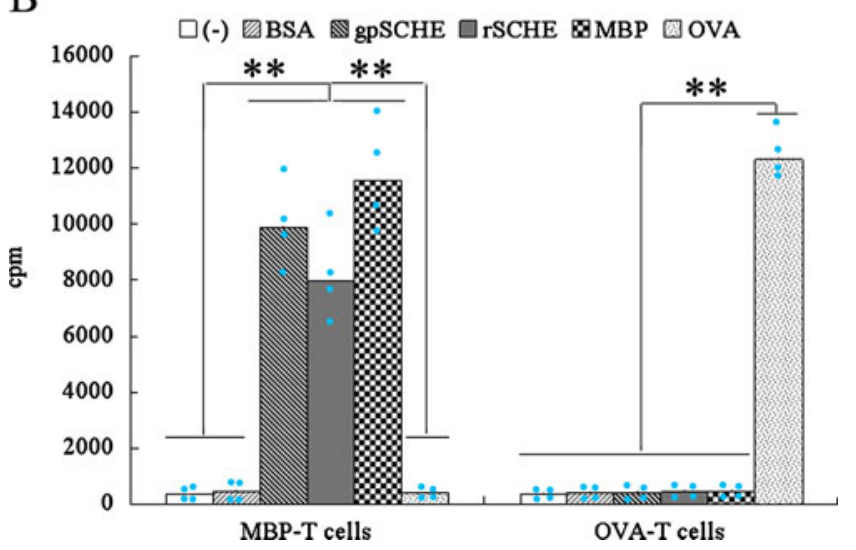

Fig. 2 Phenotypes and specificities of myelin basic protein (MBP)- and ovalbumin-reactive (OVA)-T cells are shown. (A) Flow cytometric analysis shows that $>98 \%$ of MBP- and OVA-T cells are $\mathrm{CD} 3^{+} \mathrm{CD} 4^{+} \mathrm{T}$ cells; (B) MBP- and OVA-T cells were cultured in RPMI 1640 medium only (-), stimulated by MBP, spinal cord homogenate extract (rSCHE), gpSCHE and a non-central nervous system antigen (bovine serum albumin) to show reactivity as detected by $3 \mathrm{H}$-thymidine $\left({ }^{3} \mathrm{H}-\mathrm{TdR}\right)$ incorporation. Data are median values (histograms) and individual data points (dots); $(\mathrm{n}=4) ; * *<<0.01$. BSA=bovine serum albumin

(Fig. 2B). This result indicated that MBP-T cells generated in this study were antigen-specific in the spinal cord. It should be noted, however, that the MBP antigens used to generate MBP-T cells from rats were of a guinea pig origin, and MBP-T cells also recognized antigens in rSCHE. However, the reactivity was somewhat decreased compared with that of gpSCHE.

Cytokine and Neurotrophin Expression in rSCHE-Stimulated MBP-T Cells in Vitro

To study cytokine and neurotrophin expression in MBPand OVA-T cells that were stimulated with CNS antigens, we stimulated MBP- and OVA-T cells with rSCHE or their respective antigens for 2 days in vitro to mimic the activation of these cells in vivo. Then, the expression of IFN- $\gamma$, IL-4, IL-10, IL-13, BDNF, NT-3, and NGF in MBP- and OVA-T cells was analyzed using ELISAs. As shown in Fig. 3, MBP- and OVA-T cells that were treated 

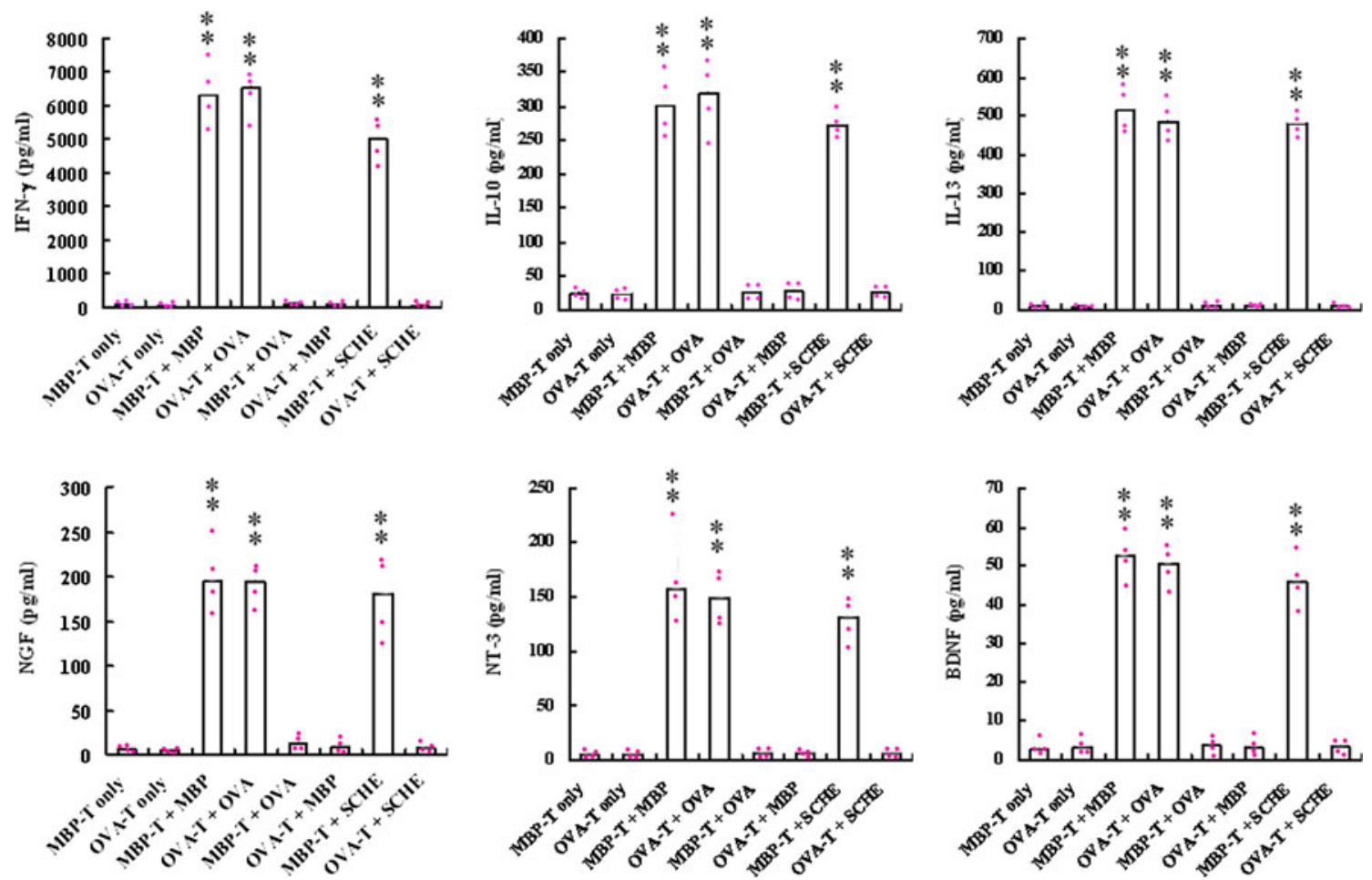

Fig. 3 Cytokine and neurotrophin production by spinal cord homogenate extract (rSCHE)-stimulated myelin basic proteinactivated $\mathrm{T}$ (MBP-T) cells in vitro. MBP- and ovalbumin-reactive activated $\mathrm{T}$ (OVA-T) cells were stimulated with rSCHE or their immunized antigens for 2 days in vitro. Concentrations of interferon (IFN)- $\gamma$, interleukin (IL)-4, IL-10, IL-13, brain-derived neurotrophic

with PBS showed no detectable expression of these cytokines and neurotrophins. After stimulation with their respective antigens, both $\mathrm{MBP}$ - and OVA-T cells expressed IFN- $\gamma$, IL-10, IL-13, BDNF, NT-3, and NGF. After stimulation with rSCHE, expression of IFN- $\gamma$, IL-10, IL-13, BDNF, NT-3, and NGF was detected in MBP-T cells. However, there was no detectable expression of the above cytokines and neurotrophins in SCHE-stimulated OVA-T cells. Interestingly, IL-4 was not detected in any group.

Effect of MBP-T Cell Transfer and NSC Transplantation on Cytokine and Neurotrophin mRNA Expression in Injured Spinal Cord Tissue

To investigate the effect of MBP-T cell transfer and NSC transplantation on cytokine and neurotrophin mRNA expression in the injured spinal cord, we transplanted GFP-NSCs and Olig2-GFP-NSCs into MBP-T- and OVA-T cell-transferred spinal cord injured rats. Two weeks after adoptive immunity (5 days after NSC transplantation), mRNA expression of IFN$\gamma$, IL-1 $\beta$, TNF- $\alpha$, IL-4, IL-10, IL-13, BDNF, NT-3, and NGF in whole injured spinal cord tissues was analyzed using RTPCR. As shown in Fig. 4, mRNA expression of IFN- $\gamma$, IL- $1 \beta$, TNF- $\alpha$, IL-10, IL-13, BDNF, NT-3, and NGF in injured factor (BDNF), nerve growth factor (NGF), and neurotrophin-3 (NT3 ) in medium supernatants were measured using enzyme-linked immunosorbent assays (ELISAs). Data are median values (histograms) and individual data points (dots); $(n=4) ; * * p<0.01$. SCHE $=$ spinal cord homogenate extract

spinal cord tissue was detected in all groups. Furthermore, mRNA expression of IL-10 and IL-13 showed no statistical significant difference between all OVA-T cell-transferred groups and the control group $(p>0.05)$. However, the injured spinal cord tissues from all MBP-T-cell-transferred groups expressed increased mRNAs for IL-10 and IL-13 compared with those of OVA-T-cell-transferred and control rats $(p<0.01)$. mRNA expression of BDNF, NT-3, and NGF showed no statistical significant difference between the OVAT-cell-transferred group and control group $(p>0.05)$. However, injured spinal cord tissues from all NSC transplanted groups (GFP-NSCs and Olig2-GFP-NSCs), and the MBP-T-celltransferred group, expressed increased mRNAs for BDNF, NT-3, and NGF compared with those of the OVA-T-celltransferred group and control group $(p<0.01)$. Interestingly, although IFN- $\gamma$, IL- $1 \beta$, TNF- $\alpha$ and IL-4 mRNA were detected in all groups, no significant difference was found between groups.

Effect of MBP-T-Cell Transfer and NSC Transplantation on T-Cell Infiltration into Injured Spinal Cords

To observe the effect of MBP-T cell transfer and NSC transplantation on local inflammatory and immune 

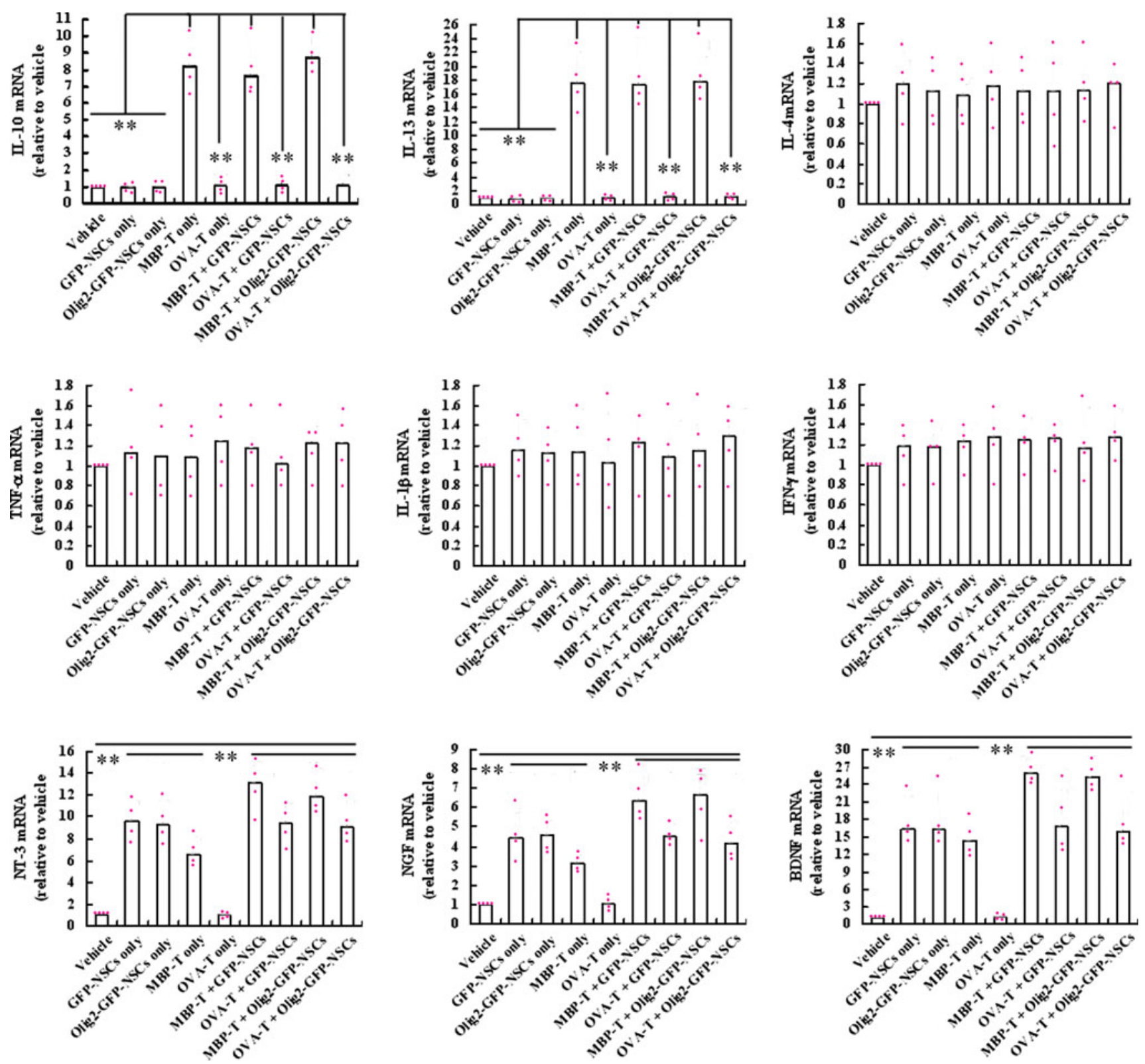

Fig. 4 Cytokine and neurotrophin mRNA expression in injured spinal cords is shown. mRNA expression was measured by real-time RT-PCR. Relative expression levels of target mRNA in various tissue samples was calculated based on the ${ }^{\Delta \Delta} \mathrm{Ct}$ method. Data are expressed relative to the injured spinal cord without T-cell transfer, which is designated as one.

responses in host rats, we examined the infiltration of T-cell subsets in the injured spinal cord at 1, 3, 7, 14, and 28 days postinjury (dpi). As shown in Fig. 5A, T cells that were isolated from the injured spinal cord were mainly $\mathrm{CD}^{+} \mathrm{CD}^{+}{ }^{+}$T-cell subsets $(>90 \%)$. T-cell infiltration into injured spinal cords was further examined using immunofluorescence staining for $\mathrm{CD} 4$ in spinal cord sections. $\mathrm{CD} 4^{+}$ $\mathrm{T}$ cells were very infrequent in intact spinal cord. However, $\mathrm{CD}^{+} \mathrm{T}$ cells were detected in the lesion epicenter of all groups at all observed time points. Figure $5 \mathrm{~B}$ shows
Data are median values (histograms) and individual data points (dots); $(n=4) ; * * p<0.01$. BDNF=brain-derived neurotrophic factor; GFP$\mathrm{NSCs}=$ green fluorescent protein erexpressing Neural Stem Cells; IL= interleukin; $\mathrm{MBP}=$ myelin basic protein; $\mathrm{NGF}=$ nerve growth factor; OVA-T $=$ ovalbumin-reactive activated $\mathrm{T} ; \mathrm{TNF}=$ tumor necrosis factor

representative images of control, MBP-, and OVA-T celltransferred groups without NSC transplantation at 3, 7, and 28 dpi. Figure 5C shows the representative images of control, MBP-, and OVA-T cell-transferred groups with NSC transplantation at 14 and 28 dpi (5 and 19 days postNSC transplantation). Statistical graphs (Fig. 5D) indicated that the trends of T-cell infiltration were similar in all groups. $\mathrm{CD}^{+} \mathrm{T}$ cells were observed at $1 \mathrm{dpi}$, and then gradually increased to a maximum at $7 \mathrm{dpi}$, followed by a decrease at 14 dpi. However, $\mathrm{CD}^{+}{ }^{+} \mathrm{T}$-cell density among 
A
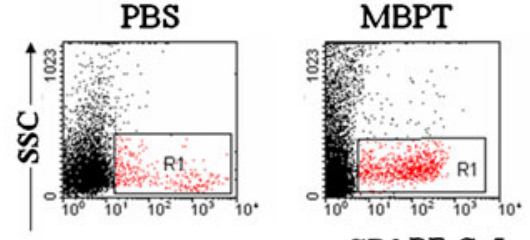

CD3-PE-Cy5
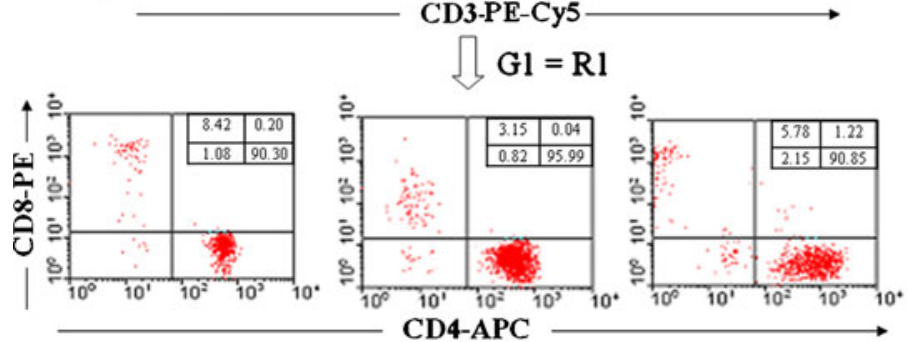

CD4-APC

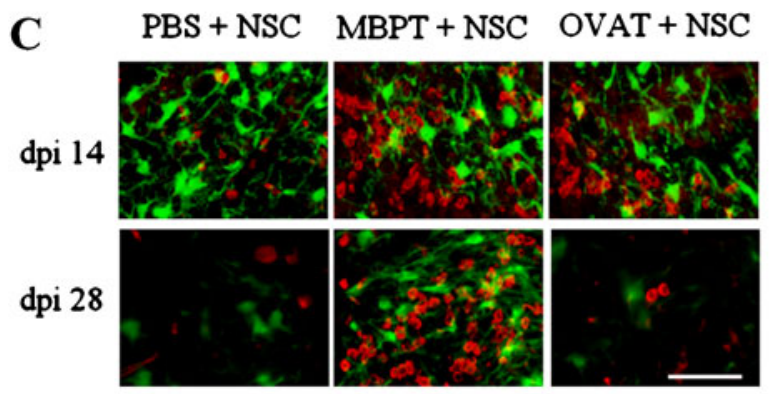

CD4 GFP
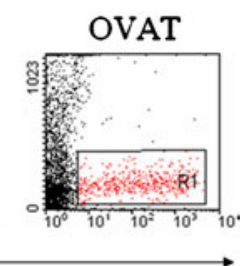
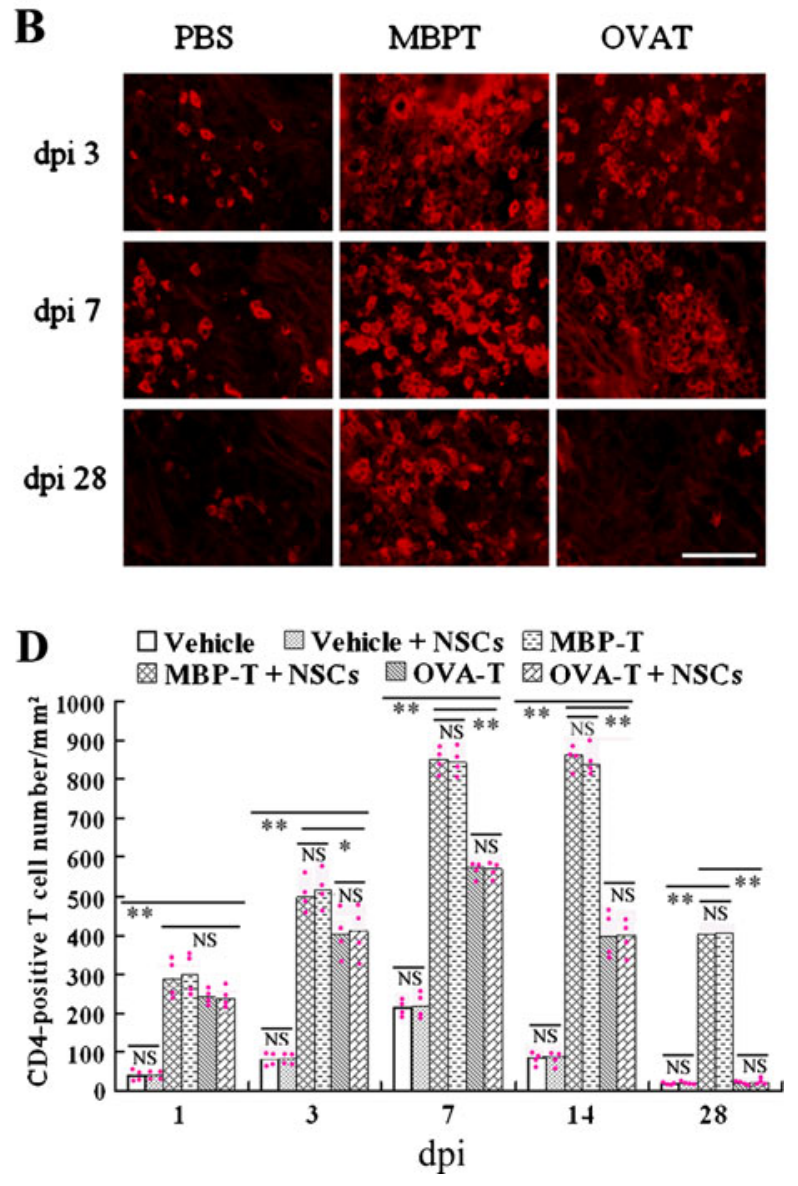

groups with NSC transplantation at 14 and 28 dpi (5 days and 19 days post-NSC transplantation). Scale bars: $25 \mu \mathrm{m}$. (d) Statistical graphs indicate that the trends of $\mathrm{T}$ cell infiltration are similar in all groups. Data are median values (histograms) and individual data points (dots); $(\mathrm{n}=4) ;{ }^{*} p<0.05 ; * * p<0.01 . \quad \mathrm{APC}=$ allophycocyanin; $\mathrm{GFP}=$ green fluorescent protein; $\mathrm{MBPT}=$ myelin basic protein-activated $\mathrm{T}$; $\mathrm{NSCs}=$ neural stem cells; OVAT $=$ ovalbumin-reactive activated $\mathrm{T}$; $\mathrm{PBS}=$ phosphate-buffered saline

that no significant difference in $\mathrm{CD} 4^{+}$T-cell density was found between NSC-transplanted groups and their corresponding groups without NSC transplantation $(p>0.05)$ (Fig. 5B-D). Because MBP-activated T cells were mainly $\mathrm{CD}^{+} \mathrm{CD}^{+} \mathrm{T}$ cells, the previous results indicated that T-cell infiltration into injured spinal cords may primarily consist of transferred MBP-T cells. $\mathrm{CD} 8^{+} \mathrm{T}$ cells were not detected in any group, which indicated that allogeneic NSC transplantation caused a very weak inflammatory response in the spinal cord.

Effect of MBP-T-Cell Transfer and NSC Transplantation on the Polarization of CNS Macrophages in the Injured Spinal Cord

To observe the effect of MBP-T-cell transfer and NSC transplantation on the local immune response of CNS macro- 
phages (resident microglia and/or macrophages derived from infiltrating monocytes), we examined the phenotypes of distinct macrophage subsets including "classically-activated" pro-inflammatory (M1) and "alternatively-activated" antiinflammatory (M2) cells [39] using flow cytometry and immunohistochemistry. As shown in Fig. 6A, macrophages in the spinal cord homogenate were first defined by CD68 expression and side scattered light in a dot plot (R1). Among $\mathrm{CD} 8^{+}$macrophages, $\mathrm{CD} 86^{+} \mathrm{CD} 163^{-}$and $\mathrm{CD} 86^{-} \mathrm{CD} 163^{+}$ subpopulations represented M1 and M2 macrophages, respectively. Moreover, M1 and M2 macrophages in spinal cord sections were determined by immunofluorescence staining of CCR7 and arginase I, respectively, as shown in Fig. 6B-E. We examined subpopulations of macrophages in the injured spinal cord at $1,3,7,14$, and 28 dpi. It was reported that microglia/macrophages possess an M2 phenotype in the intact spinal cord [39]. Our result indicated that the phenotypes of both M1 and M2 macrophages were rapidly induced in the injured spinal cords of all groups (Fig. 6F). However, M1 macrophages were detected and maintained at a high level for up to $28 \mathrm{dpi}$ (the longest time period evaluated in this study) in all groups. In contrast, M2 a

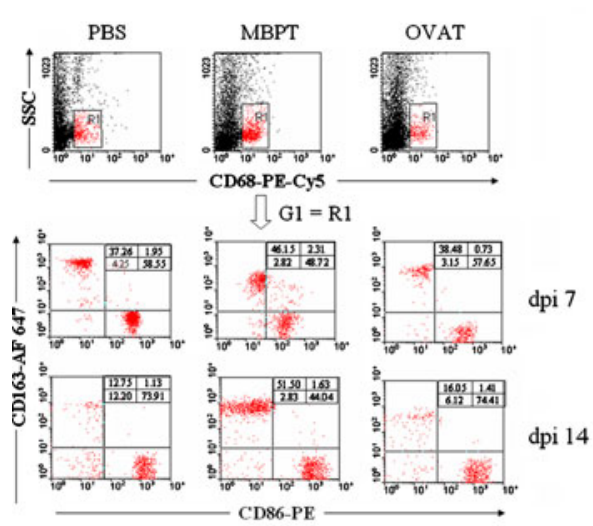

f
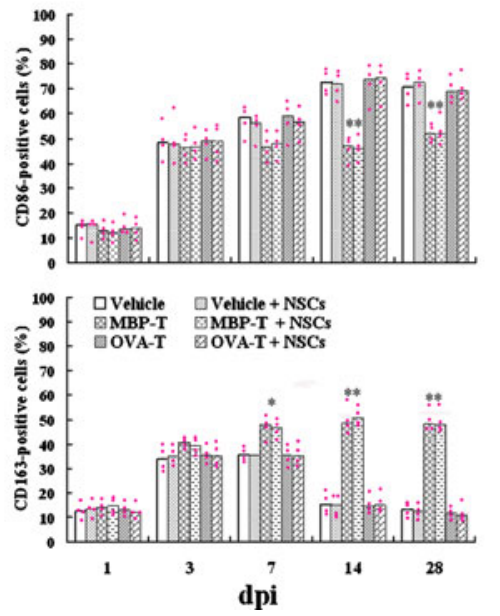

b

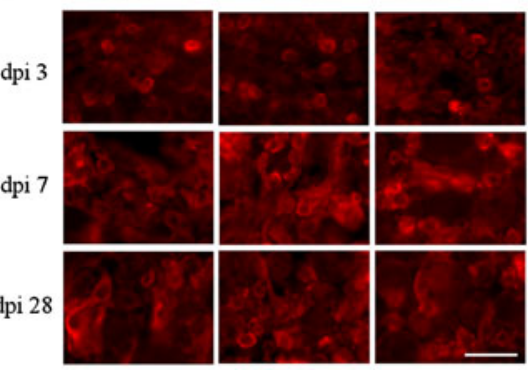

CCR7

C

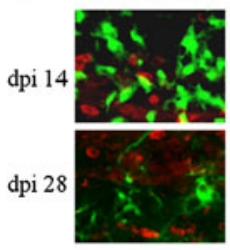

OVAT + NSC

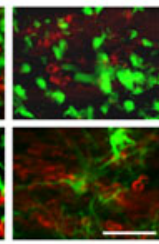

CCR7 GFP
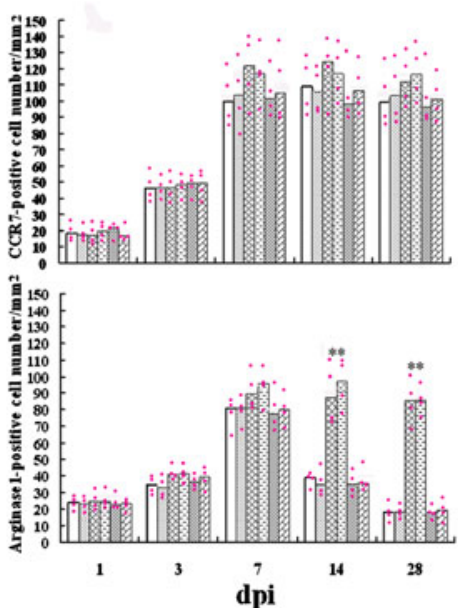

d

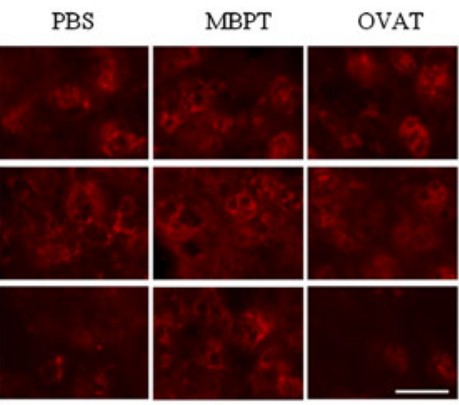

Arginase 1

e

$\mathrm{PBS}+\mathrm{NSC} \quad \mathrm{MBPT}+\mathrm{NSC} \quad$ OVAT $+\mathrm{NSC}$

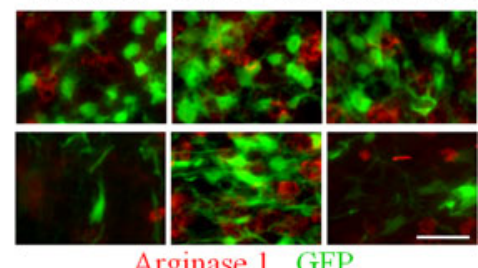

Arginase 1 GFP

g
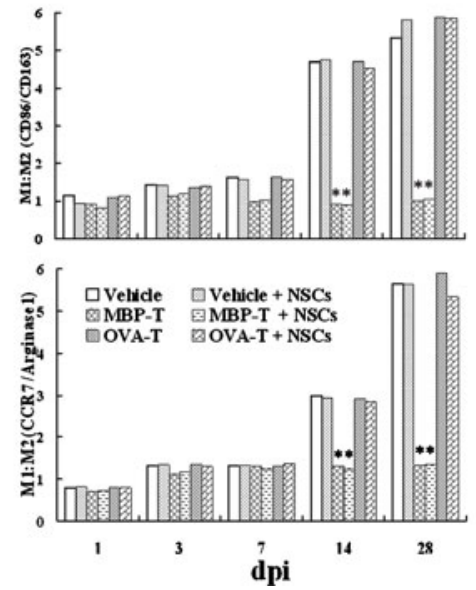

Fig. 6 Polarization of central nervous system macrophages in the injured spinal cord are shown. Phenotypes of distinct macrophage subsets in injured spinal cord were examined by flow cytometry and immunohistochemistry. (a) Among $\mathrm{CD}^{+} 8^{+}$macrophages, $\mathrm{CD} 86^{+} \mathrm{CD} 163^{-}$, and $\mathrm{CD} 86^{-} \mathrm{CD} 163^{+}$, the subpopulations are $\mathrm{M} 1$ and M2 macrophages, respectively. (b-e) M1 and M2 macrophages in the spinal cord sections were determined by CC-chemokine receptor 7 and arginase I immunofluorescence staining, respectively. Scale bars: 25 $\mu \mathrm{m}$. (f) Statistical graphs show the trends of M1 and M2 macrophages in various groups. Data are median values (histograms) and individual data points (dots); $(\mathrm{n}=4) ; * * p<0.01$. (g) Statistical graphs show the ratio of $\mathrm{M} 1: \mathrm{M} 2$ cells in various groups $(* * p<0.01)$. GFP $=$ green fluorescent protein; $\mathrm{MBPT}=$ myelin basic protein-activated $\mathrm{T}$; $\mathrm{NSCs}=$ neural stem cells; OVAT $=$ ovalbumin-reactive activated $\mathrm{T} ; \mathrm{PBS}=$ phosphate-buffered saline 
macrophages were transiently detected at high levels and returned to pre-injury levels at $14 \mathrm{dpi}$ in control and OVA-Tcell-transferred groups (with or without NSC transplantation). Only in MBP-T cell-transferred groups (with or without NSC transplantation) were M2 macrophages detected and maintained at a high level for up to $28 \mathrm{dpi}$. Expressed as a ratio of M1:M2 macrophages (Fig. 6G), the ratio was approximately equivalent in all groups at 1,3 , and 7 dpi. However, after the first week, the M1:M2 ratio markedly increased in control and OVA-T-cell-transferred groups (with or without NSC transplantation). Only in MBPT-cell-transferred groups (with or without NSC transplantation) was the ratio of M1:M2 close to the levels at 1, 3, and 7 dpi. The M1:M2 ratio in MBP-T-cell-transferred groups (with or without NSC transplantation) was significantly lower compared with that of other groups $(p<0.01)$.

Effect of MBP-T-Cell Transfer and Olig2 Overexpression on the Survival and Differentiation of NSCs in the Injured Spinal Cord

To determine the survival of transplanted GFP-NSCs and Olig2-GFP-NSCs in vivo, we detected transplanted cells by GFP fluorescence at 2 and 6 weeks post-transplantation. GFP-positive cells were observed in the spinal cords of host rats at 2 and 6 weeks post-transplantation. Because it is extremely difficult to discern individual cells at 6 weeks, we counted viable cells and determined their phenotype at 2 weeks post-transplantation. Figure $7 \alpha \beta \chi \delta \varepsilon$ and $\phi$ show representative low power images of spinal cords from the 6 groups. Transplanted GFP-positive cells (green) were mainly restricted to the dorsal white matter and part of the gray matter. Figure 7A-X shows representative high-power images of the spinal cords. Quantitative analysis showed that the average number of GFP-positive cells in the spinal cord of MBP-T-cell-transferred groups was significantly higher compared with those of other groups $(p<0.01$; Fig. 7a). However, there was no difference between the number of GFP-NSCs and Olig2-GFP-NSCs in the same transferred groups ( $p>0.05$; Fig. 7a). Next, we investigated the differentiation of transplanted GFP-NSCs and Olig2GFP-NSCs in spinal cords using immunofluorescence staining. In all GFP-NSC-transplanted groups, the majority of GFP-positive cells expressed GFAP and only a very small number of GFP-positive cells expressed $\beta$ III-tubulin and MBP (Fig. 7A-L). However, in Olig2-GFP-NSCtransplanted groups, a greater number of GFP-positive cells differentiated into MBP-positive OLs (Fig. 7M-X, b-d). The percentage of GFP/MBP-double positive cells in GFPOlig2-NSC-transplanted groups was significantly higher compared with that of other groups, while the percentage of GFP/GFAP-double positive cells was significantly decreased compared with that of other groups $(p<0.01)$.
Effect of MBP-T-Cell Transfer and Olig2-Overexpressing NSC Transplantation on the Lesion Volume of Contused Spinal Cord

Quantitative analysis of the total lesion volume of injured spinal cords was performed after 7 weeks of SCI. As shown in Fig. 8, total lesion volumes in MBP-T cell-transferred groups, GFP-NSC-, and GFP-Olig2-NSC-transplanted groups were significantly lower compared with those of groups treated with PBS and transferred with OVA-T cells alone $(p<0.05)$. There were no significant differences between the PBS control and OVA-T cell transfer alone $(p>0.05)$. GFP-NSC and Olig2-GFP-NSC transplantation showed no significantly different effect on the total lesion volume of the injured spinal cords $(p>0.05)$. There were also no significant differences among the 3 MBP-T cell-transferred groups ( $p>0.05$ ).

Effect of MBP-T-Cell Transfer and Olig2-Overexpressing NSC Transplantation on the Survival of Motoneurons in the VH following SCI

To determine the effect of MBP-T-cell transfer and Olig2overexpressing NSC transplantation on neuronal survival, the numbers of $\mathrm{VH}$ motor neurons at the injury epicenter as well as at 1-, 2-, 3-, and 4-mm rostral and caudal to the epicenter were counted after 7 weeks of SCI. As shown in Fig. 9, in the 3 MBP-T-cell-transferred groups, as well as the GFP-NSC- and GFP-Olig2-NSC-transplanted groups, a higher number of residual motor neurons were found in the $\mathrm{VH}$ at 3- and 4-mm rostral and caudal to the lesion epicenter compared with those of groups treated with PBS and OVA-T-cell transfer alone $(p<0.01)$. Further comparison showed that MBP-T-cell transfer combined with GFPNSC or GFP-Olig2-NSC transplantation resulted in significantly reduced neuronal loss compared with that of any treatment alone $(p<0.05)$. However, the number of motor neurons showed no significant difference between the PBS control and OVA-T-cell transfer alone, and between GFPNSC and Olig2-GFP-NSC transplantation with the same Tcell transfer $(p>0.05)$.

Effect of MBP-T-Cell Transfer and Olig2-Overexpressing NSC Transplantation on the Extent of Myelination following SCI

To investigate the effect of MBP-T-cell transfer and Olig2overexpressing NSC transplantation on myelin preservation and the extent of residual myelination, stained with LFB, was examined at the injury epicenter as well as at 1-, 2-, 3-, and 4-mm rostral and caudal to the injury epicenter after 7 weeks of contusive SCI. As shown in Figure 10, in the 3 MBP-T-cell-transferred groups, the volume of residual myelin was significantly increased at the epicenter and at 


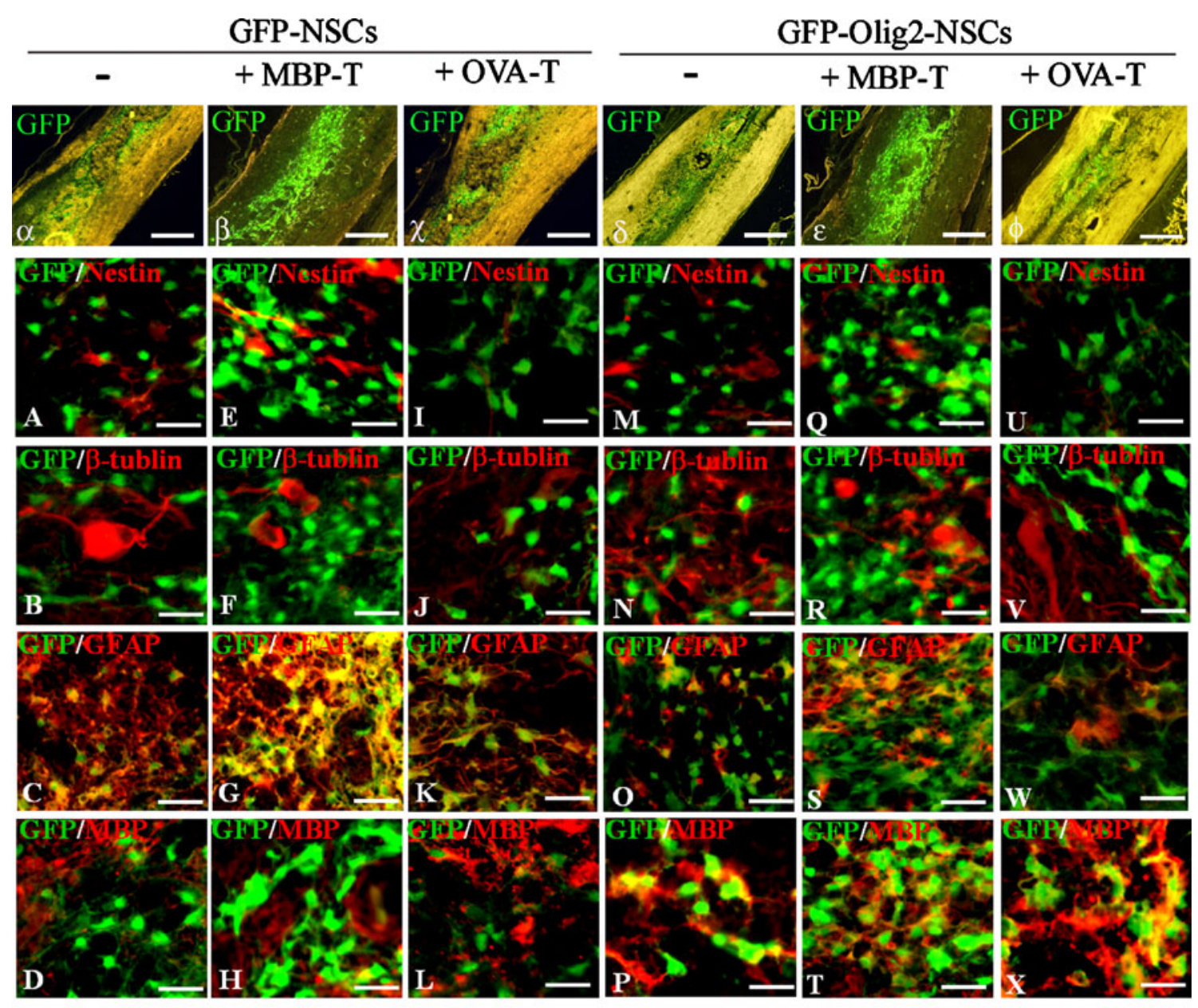

a

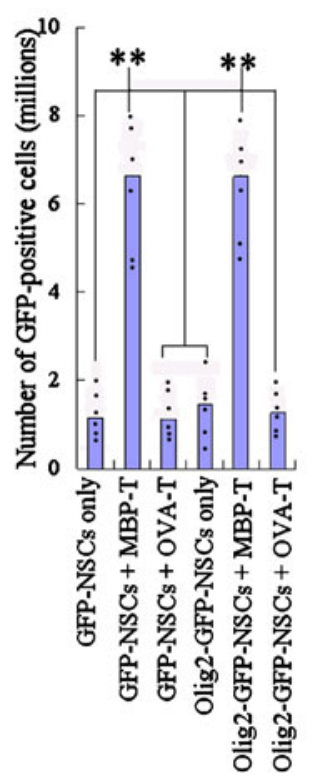

b

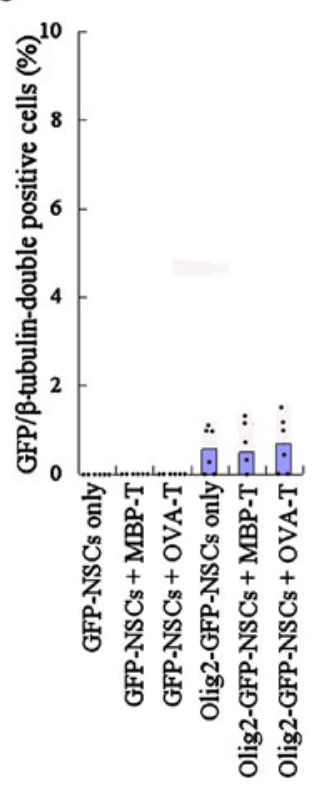

c

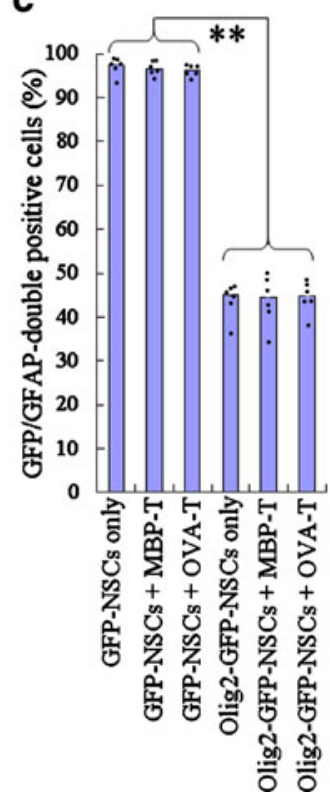

d

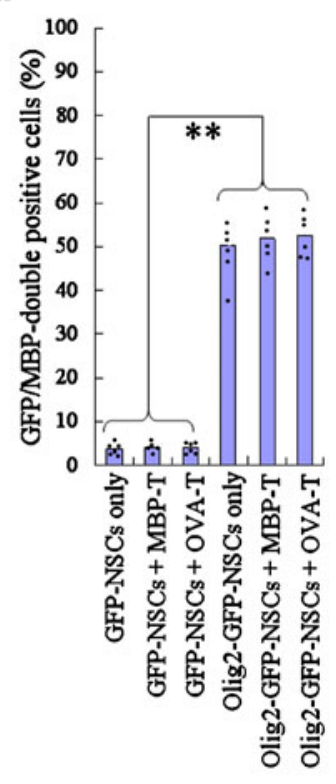


Fig. 7 The survival and differentiation of neural stem cells (NSCs) after 2 weeks of transplantation into injured spinal cords are shown. Two weeks after cell transplantation, the survival and differentiation of transplanted cells were detected in sagittal sections of injured spinal cord. $(\alpha \beta \chi \delta \varepsilon$ and $\phi$ Representative low-power images show the survival and distribution of transplanted cells (green). Scale bar $=1$ $\mathrm{mm}$. (A-X) Representative merged images show surviving green fluorescent protein (GFP)-positive cells and their differentiation fate. Cell specific markers (nestin, $\beta$ III-tubulin, glial fibrillary acidic protein [GFAP], and myelin basic protein [MBP]) are red. Cell specific markers and GFP (green)-double positive cells are yellow. Scale bar $=25 \mu \mathrm{m}$. (a-d) Statistical graphs show the number of GFPpositive cells (a), percentages of nestin (b), GFAP (c), and MBP (d) positive cells in GFP-positive cells. Data are median values (histograms) and individual data points (dots); $(\mathrm{n}=6) ; * * p<0.01$. MBP-T $=$ myelin basic protein-activated-T; OVA-T $=$ ovalbumin-reactive activated- $\mathrm{T}$

1-mm rostral, as well as 1- and 2-mm caudal to the epicenter compared with that of groups treated with PBS and OVA-T cell transfer alone $(p<0.01)$. However, the volume of residual myelin showed no significant difference between the PBS control and OVA-T-cell transfer alone. Although Olig2-GFPNSC-transplanted groups showed a slightly higher volume of residual myelin compared with that of GFP-NSCtransplanted groups with the same passive transfer, there was no significant difference between the groups $(p>0.05)$.

To verify LFB results, a subset of sections from the injury epicenter was stained with toluidine blue. As shown in Fig. 11A, the spinal cord contusion injury resulted in widespread demyelination. However, myelinated axons were more abundant in MBP-T-cell-transferred rats compared with those of other groups. To further confirm the cellular source of regenerated myelin, OL-remyelinated axons (Fig. 11A, arrowheads) were identified by characteristically thin myelin sheaths that are relative to the axon diameter, with a $0.1-$ to 0.4- $\mu \mathrm{m}$ myelin sheath thickness [40-42]. Schwann cell (SC)remyelinated axons (Fig. 11A, arrows) were identified by characteristically thick myelin sheaths relative to the axon diameter, with a 0.6 - to $1.2-\mu \mathrm{m}$ myelin sheath thickness, darker myelin staining relative to OL myelin, and the cell body immediately juxtaposed to the myelin sheath [40-42]. We counted OL- and SC-remyelinated axons in 4 random $10 \times 40$-fold microscope views $\left(\sim 67,500 \mu^{2}\right.$ per view $)$ in the middle of the lesion and pial borders in the dorsal, lateral, and ventral columns. The number of OL-remyelinated axons in the GFP-Olig2-NSC and MBP-T-cell groups was significantly higher compared with those of all other groups (Fig. 11B; $p<0.05)$. The numbers of SC-remyelinated axons in the three MBP-T-cell-transferred groups were significantly higher compared with those of all other groups (Fig. 11B; $p<0.01$ ).

Transplanted Olig2-Overexpressing NSCs Remyelinate Axons in the Injured Spinal Cord

All transplanted NSCs expressed GFP; thus, we used GFP as a marker to directly detect whether mature OLs derived from transplanted NSCs were able to form a myelin sheath around axons. We found that $\sim 4 \%$ of transplanted GFPNSCs and $\sim 50 \%$ of transplanted GFP-Olig2-NSCs were
Fig. 8 Three-dimensional reconstruction of lesion volumes after 7 weeks of contusive spinal cord injury is shown.

(A) Representative images of a three-dimensional reconstruction of a 10 -mm spinal cord segment containing the lesion cavity (green). Spinal cord contours and white matter are shown in semitransparent blue, and gray matter is depicted in gray. (B) Data are median values (histograms) and individual data points (dots); $(\mathrm{n}=6) ;{ }^{*} p<0.05$. GFP-NSC $=$ green fluorescent protein neural stem cells; MBPT $=$ myelin basic protein-activated $\mathrm{T}$; $\mathrm{NSC}=$ neural stem cells; OVAT $=$ ovalbumin-reactive activated $\mathrm{T}$ a
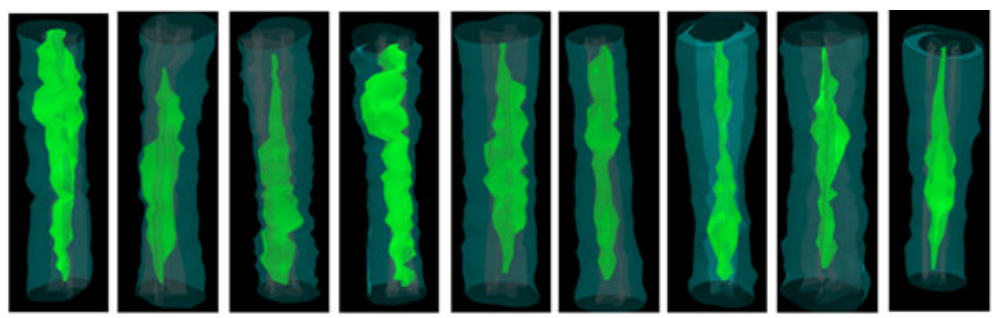

b

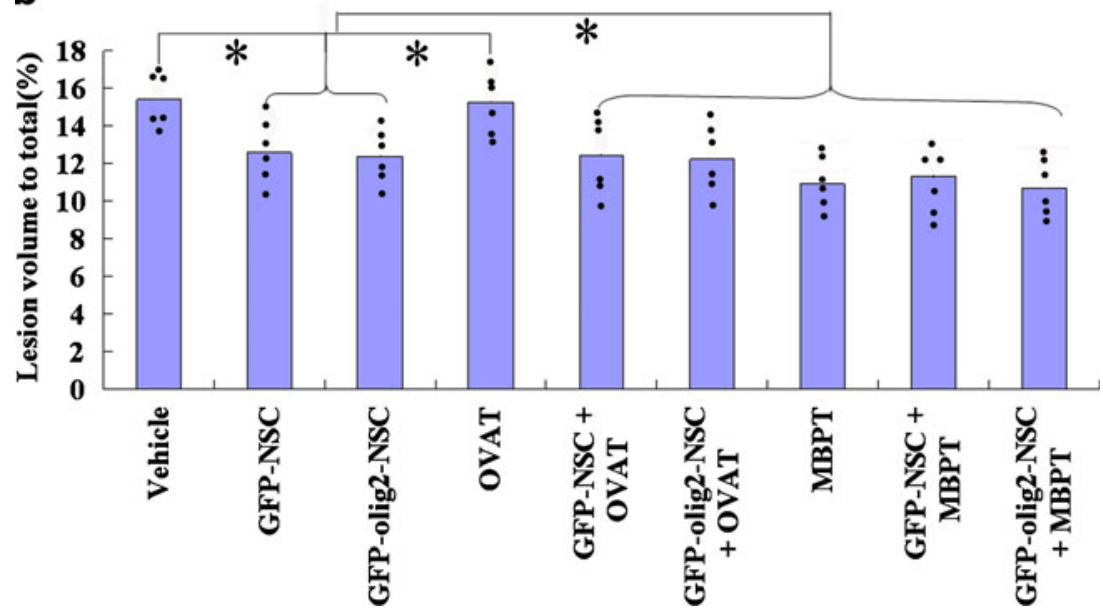


Fig. 9 Survival of motoneurons in the spinal cord ventral horn (VH) after 7 weeks of contusive spinal cord injury is shown. (A, $\mathrm{a}, \mathrm{B}$, and b) Neutral red staining shows VH neurons in sections from the myelin basic proteinactivated T (MBPT)-cell-transferred group, some VH neurons (arrows) remain intact in a section 8-mm rostral to the epicenter $(\mathrm{A}, \mathrm{a})$, whereas at the injury epicenter $(\mathrm{B}, \mathrm{b})$ neurons were not found. Scale bar in (A and $\mathrm{B})=1 \mathrm{~mm}$ and $(\mathrm{a}$ and $\mathrm{b})=25$ $\mu \mathrm{m}$. (C) Comparison of $\mathrm{VH}$ neurons among groups at various distances from the injury epicenter (0), as well as at 1-, 2-, $3-$, at 4-mm rostral $(+)$ and caudal $(-)$ to the epicenter. Data are median values (histograms) and individual data points (dots); $(\mathrm{n}=6) ;{ }^{*} p<0.05,{ }^{*} p<$ 0.01 . GFP $=$ green fluorescent protein; $\mathrm{NSC}=$ neural stem cells; OVAT $=$ ovalbumin-reactive activated $\mathrm{T}$
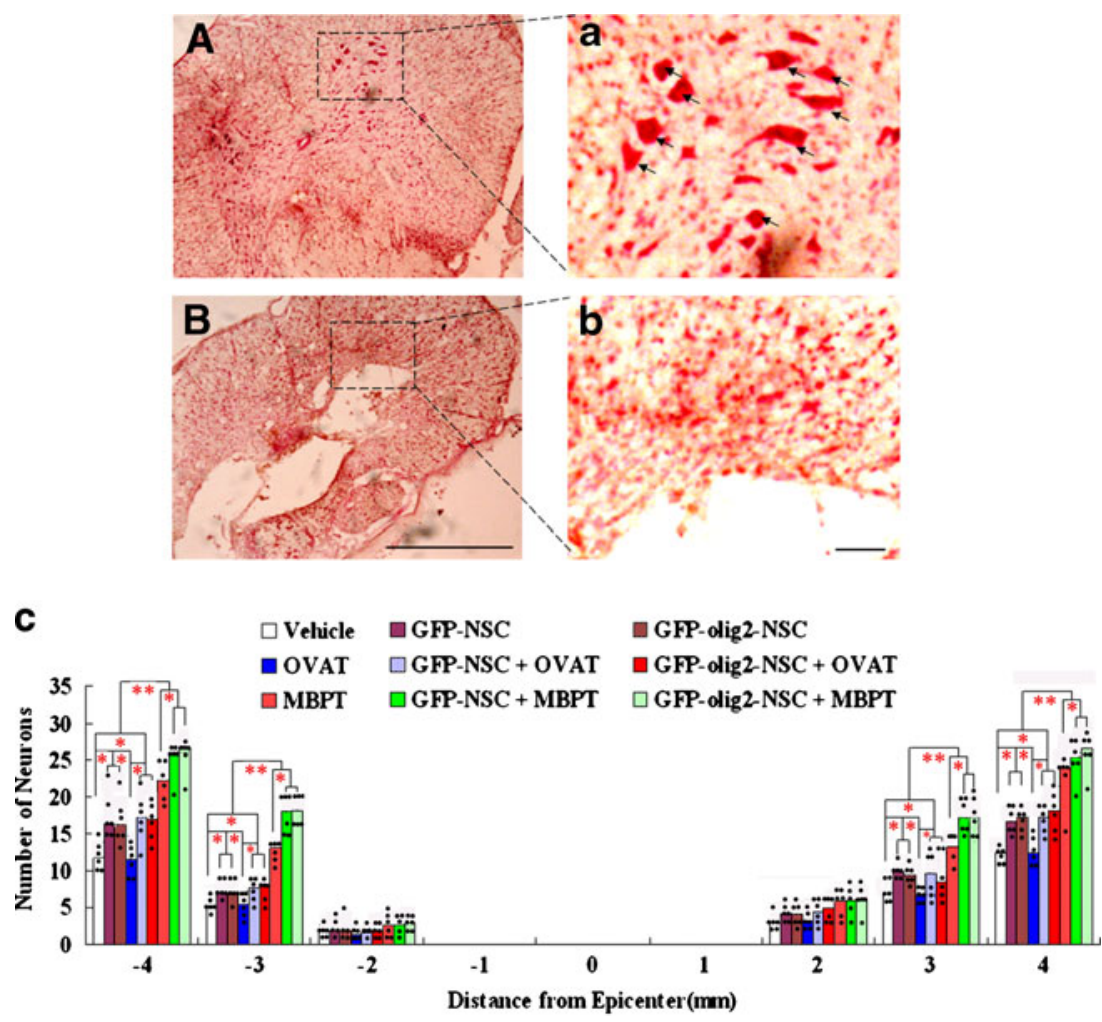

differentiated into MBP-positive OLs in all groups (Fig. 12A, arrows), which formed multiple rings around NFM-positive axons as observed in cross sections (Fig. 12A, arrows). We further confirmed transplanted NSC-derived OL remyelination using immuno-EM. In GFP-Olig2-NSC transplanted groups, GFP-positive cells showed ultrastructural characteristics of mature OLs, which sent processes to wrap multiple adjacent axons (Fig. 12B). GFP immunoreactivity was directly detected in myelin at higher magnifications (Fig. 12C, arrows), indicating remyelination was derived from transplanted NSCs. However, in GFP-NSC transplanted groups, although GFP-positive cells were also found, ultrastructural characteristics of mature OLs were very infrequent (Fig. 12D). GFP immunoreactivity was mainly detected in cell bodies at higher magnifications (Fig. 12E, arrows), indicating that those transplanted cells could not form myelin.

\section{Effect of MBP-T-Cell Transfer and Olig2-Overexpressing NSC Transplantation on Functional Recovery in Rats after SCI}

To observe the effect of MBP-T-cell transfer and Olig2overexpressing NSC transplantation on functional recovery in spinal cord injured rats, BBB scores were evaluated. As shown in Fig. 13A, all animals scored 21 points prior to SCI. At 1 day post-SCI, all animals received a score of 0 , and at 3 days a score $<2$. During the following days, locomotor performance was substantially improved and plateaued in the third week. From weeks 3 to 7, BBB scores in MBP-T-cell transfer combined with GFP-NSC or Olig2GFP-NSC transplantation groups were consistently higher compared with those of other groups $(p<0.01)$ and differences between the MBP-T-cell transfer only group and other groups were also statistically significant $(p<0.05)$. Notably, in the same PBS control and OVA-T-cell-transferred groups, there were no significant differences between Olig2-GFP-NSC- and GFP-NSC-transplanted groups ( $p>$ 0.05 ). The correlation between the final histological outcomes and behavioral scores for each individual animal in all groups was also analyzed (6 rats in each group; $n=54$ ). Total lesion volume was strongly negatively correlated with BBB scores at 7 weeks post-SCI (Fig. 13B; $r=-0.82 ; p<0.01$ ). The volume of residual myelin at the epicenter (Fig. 13C; $r=$ $0.94 ; p<0.01)$ and the numbers of $\mathrm{VH}$ motor neurons at $3-\mathrm{mm}$ rostral to the epicenter (Fig. 13D; $r=0.93 ; p<0.01$ ) were strongly positively correlated with $\mathrm{BBB}$ scores.

Fig. 10 Quantifications of residual myelination in the injured spinal cord after 7 week of contusive spinal cord injury is shown. (A) Luxol fast blue-stained cross-sections of a spinal cord taken from the injury epicenter (0), as well as at 1-, 2-, 3-, 4-mm rostral (+) and caudal (-) to the epicenter. (B) Comparison of residual myelination among groups at various distances from the injury epicenter. Data are median values (histograms) and individual data points (dots); $(\mathrm{n}=$ $6) ;{ }^{*} p<0.01$. GFP $=$ green fluorescent protein; MBPT $=$ myelin basic protein-activated $\mathrm{T}$; $\mathrm{NSC}=$ neural stem cells; $\mathrm{OVAT}=$ ovalbumin reactive activated $\mathrm{T}$ 
a

Vehicle
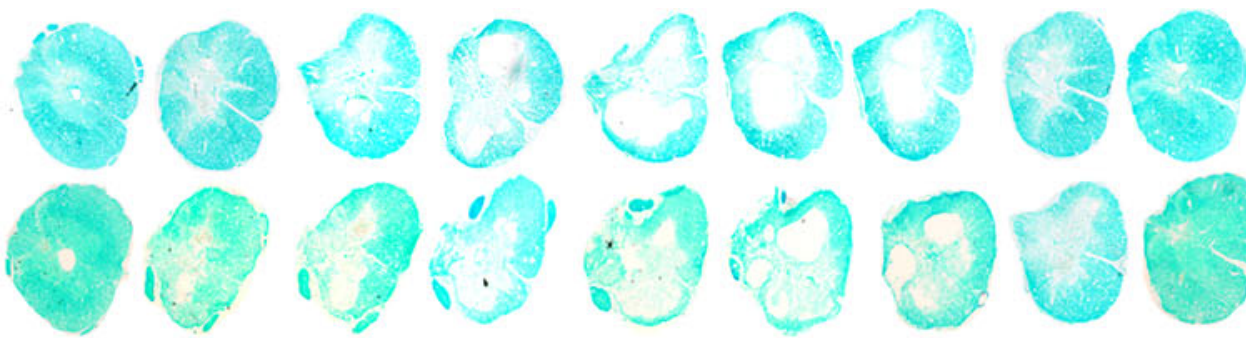

GFP-NSC

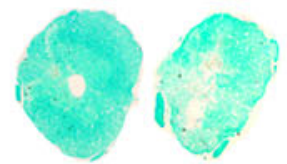

GFP-olig2-NSC
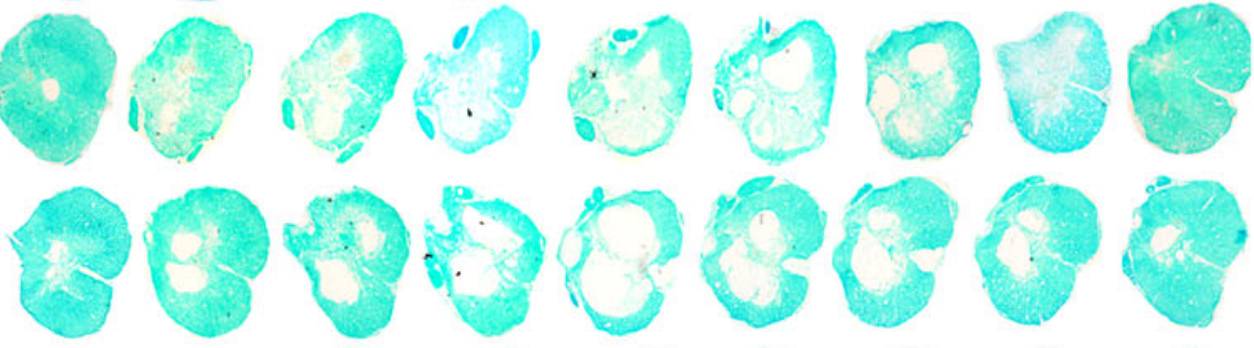

OVAT
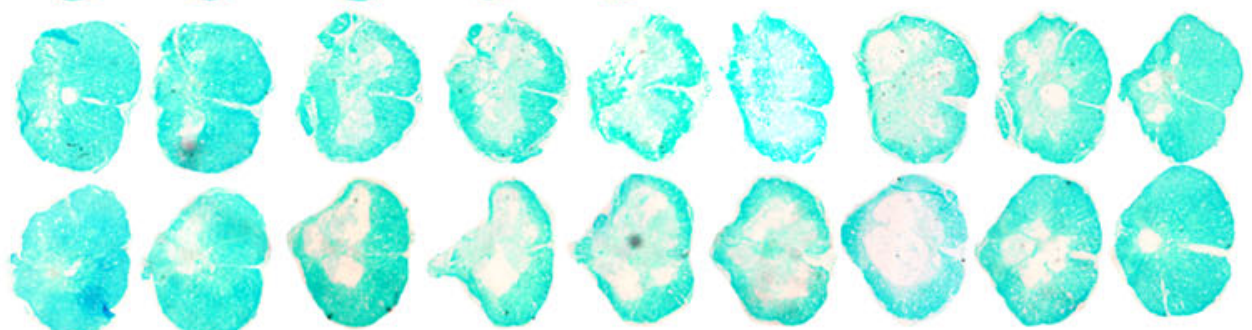

GFP-NSC
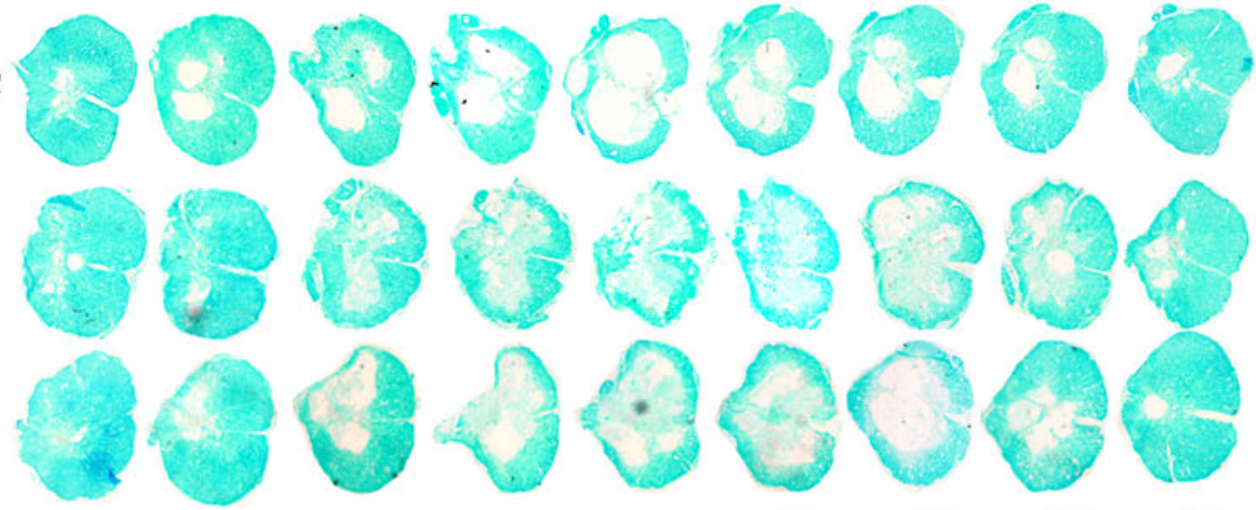

GFP-olig2-NSC

+ OVAT
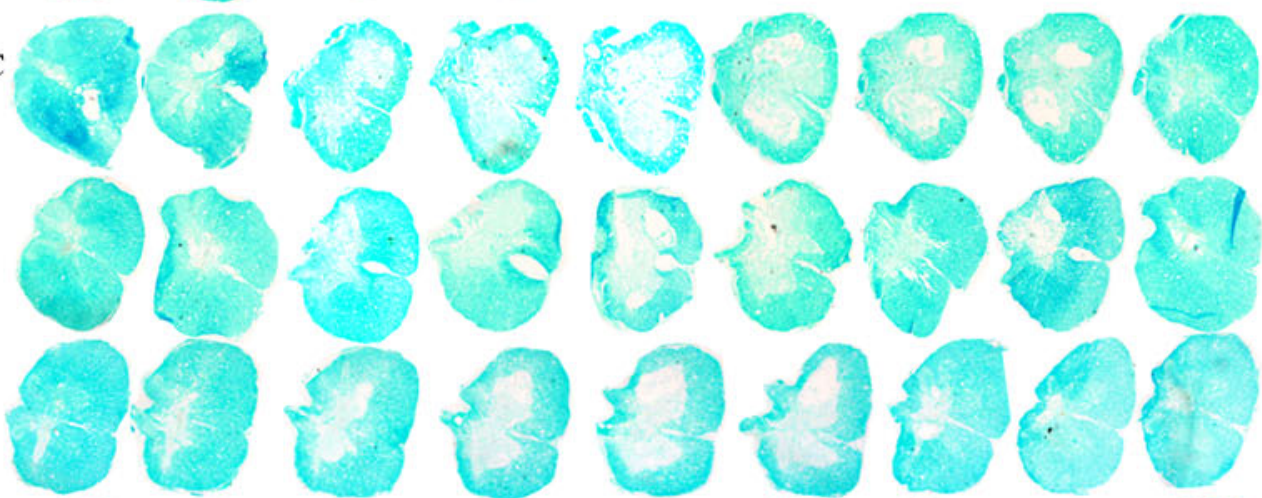

GFP-NSC

+ MBPT

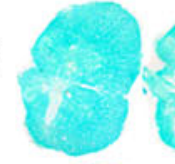

GFP-olig2-NSC

+ MBPT
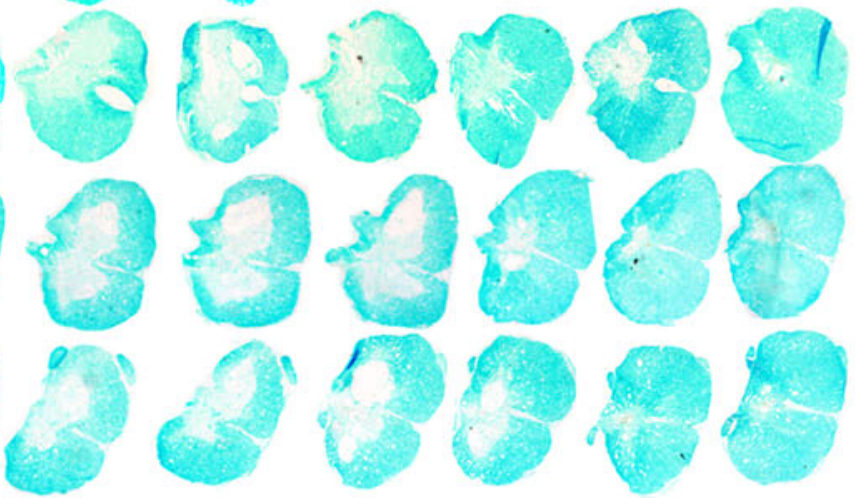

b

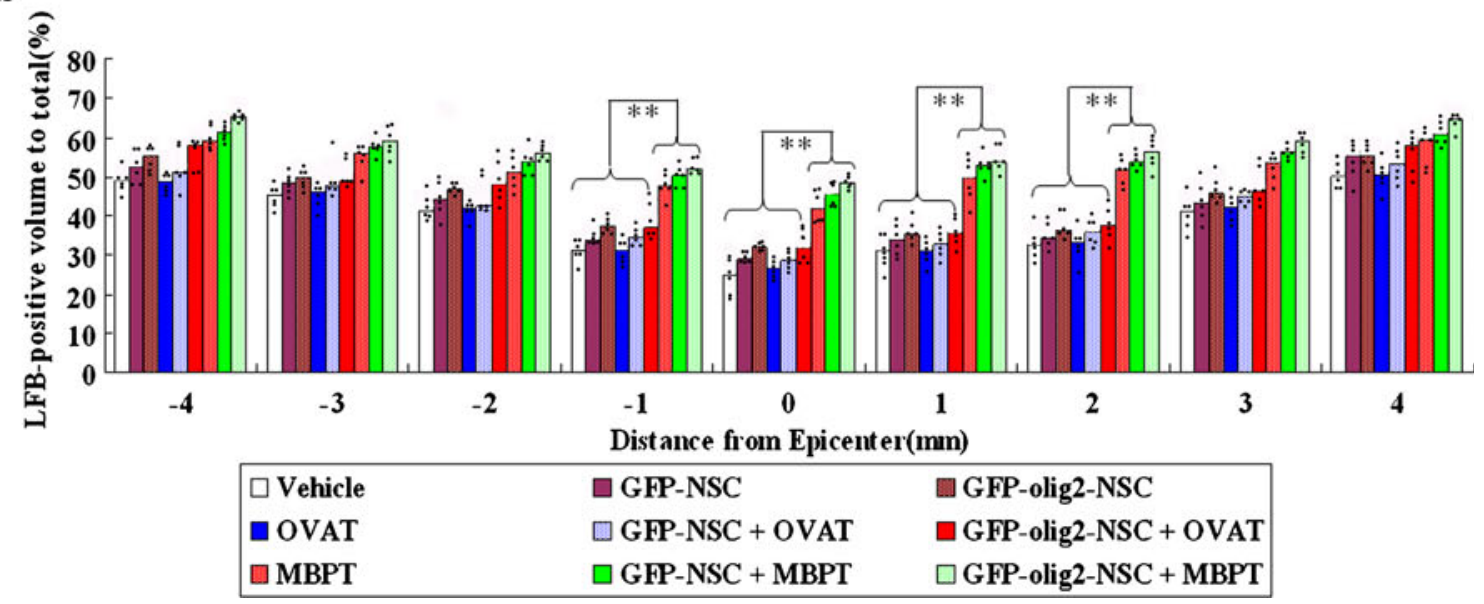


Fig. 11 Quantifications of oligodendrocyte (OL)- and Schwann cell (SC)-remyelinated axons in the injured spinal cords after 7 weeks of contusive spinal cord injury are shown. (A)

Representative

photomicrographs of toluidine blue-stained sections taken from the middle of the lesion and pial borders. OL-remyelinated

(arrowheads) and

SC-remyelinated axons (arrows) are identified by their myelin sheaths relative to the axon diameter. (B) Statistical graphs show the number of OL- and

SC-remyelinated axons in 4 random $10 \times 40$-fold microscope views in the middle of the lesion and pial borders in the dorsal, lateral, and ventral columns.

Data are median values (histograms) and individual data points (dots); $(\mathrm{n}=6) ;{ }^{*} p<0.05$,

$* * p<0.01$. GFP $=$ green

fluorescent protein;

$\mathrm{MBPT}=$ myelin basic

protein-activated $\mathrm{T}$;

$\mathrm{NSC}=$ neural stem cells;

OVAT $=$ ovalbumin-reactive

activated $\mathrm{T}$

\section{a}
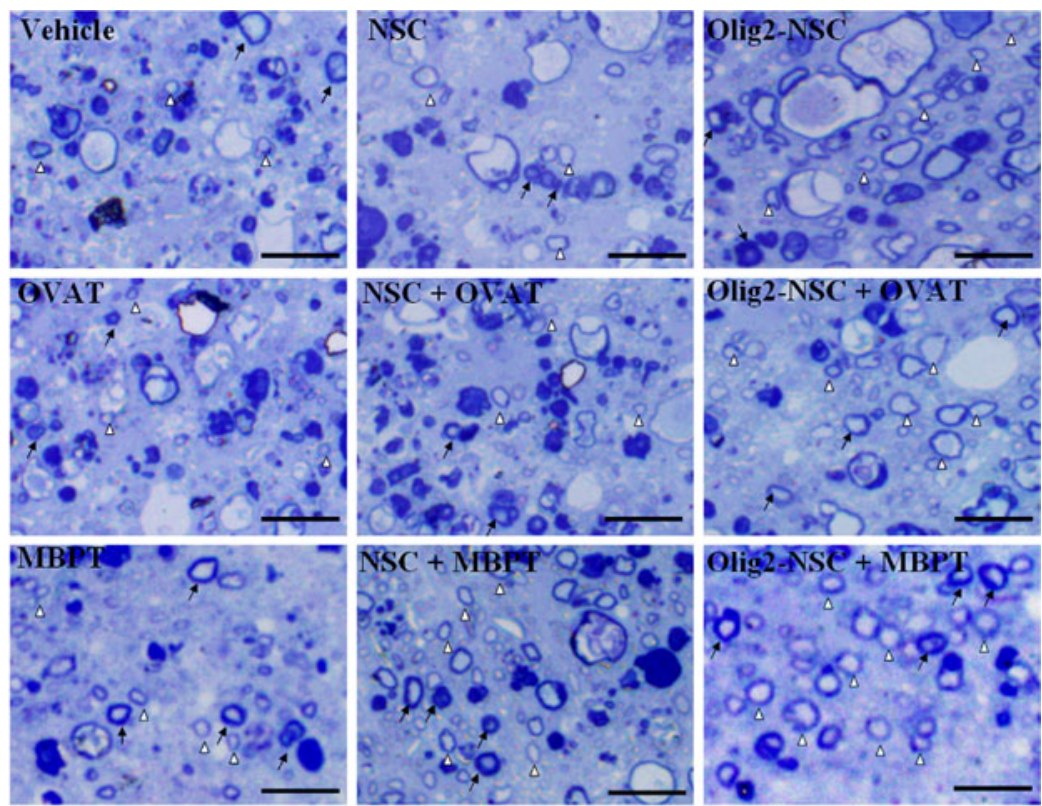

b
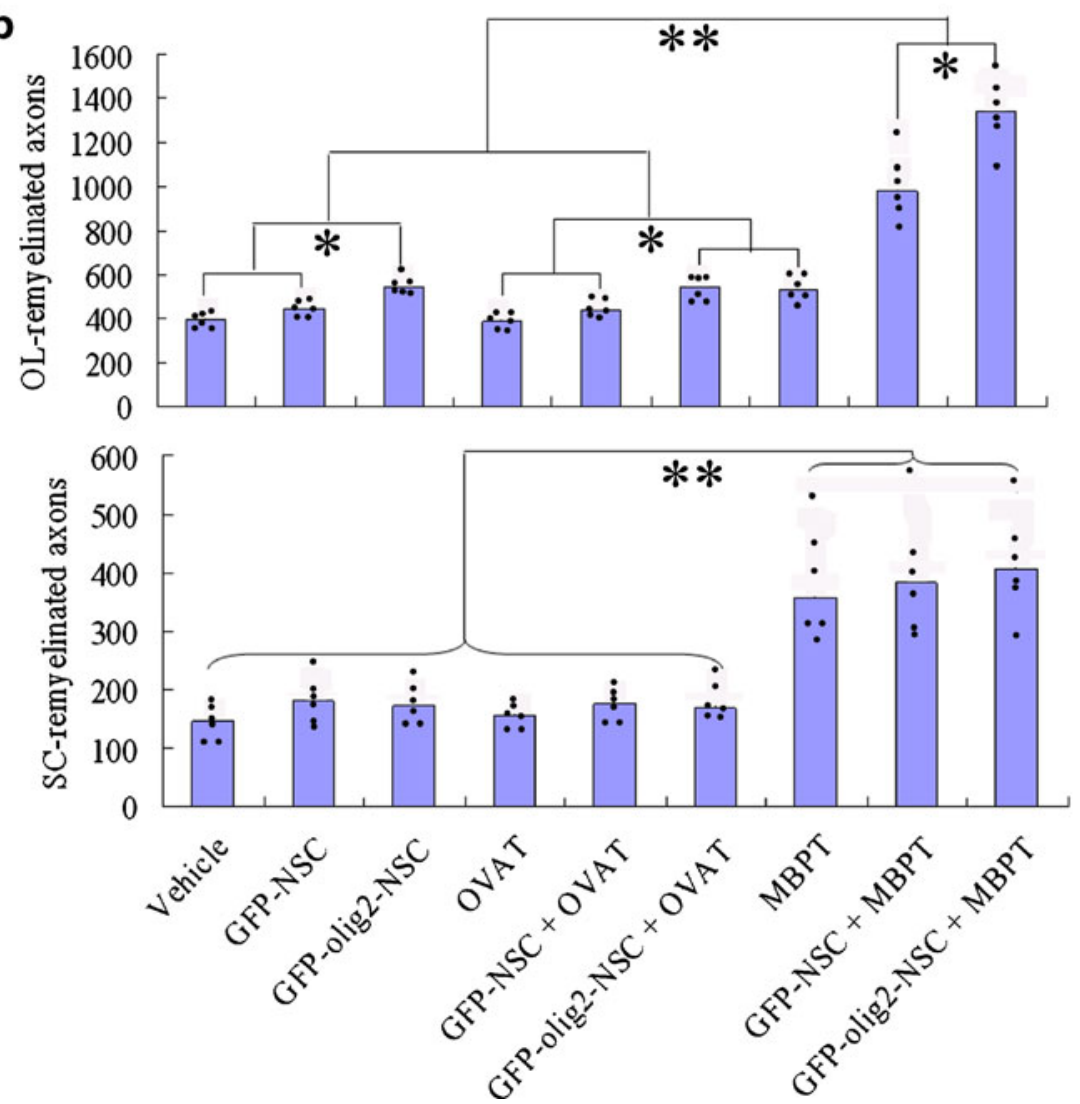

\section{Discussion}

Many axons remain intact following SCI, but are rendered useless by a loss of insulating myelin [43-45]. Cell transplantation is an attractive approach for the treatment of demyelinating diseases. Multiple types of cells including NSCs, glial-restricted precursors, and OPCs have been used for differentiation into mature OLs to induce axonal remyelination after transplantation into injured spinal cords $[35,40,46-49]$. Although approximately $15 \%$ and $47 \%$ of transplanted glial-restricted precursors and adult OPCs, respectively, differentiate into mature OLs in the injured spinal cord $[35,40]$, these cells are difficult to obtain and store for clinical application. In contrast, NSCs can be 
Fig. 12 Transplanted

Olig2-overexpressing neural stem cells (NSCs) remyelinate axons in the injured spinal cord are shown. (A) Transplanted NSCs differentiate into mature myelin basic protein (MBP)positive oligodendrocyte (OLs) (red) at various proportions (arrows), which form myelin rings around neurofilament $(\mathrm{NF})$ M-positive axons (blue). (B-E) Immuno-electron microscopy (immuno-EM) confirmed transplanted NSC-derived OL remyelination. In green fluorescent protein (GFP)-Olig2-NSCtransplanted groups $(\mathrm{B}, \mathrm{C})$, GFP-positive cells (B, asterisk) show ultrastructural characteristics of mature OLs. GFP immunoreactivity is directly detected in myelin at higher magnifications $(\mathrm{C}$, arrows). However, in GFP-NSC-transplanted groups (D, E), although GFP-positive cells are found (D, asterisk), GFP-positive cells showing ultrastructural characteristics of mature OLs are very infrequent. GFP immunoreactivity is mainly detected in cell bodies at higher magnifications (E, arrows).

Scale bars in (A): $25 \mu \mathrm{m}$, in (B and $\mathrm{D}): 10 \mu \mathrm{m}$, and in $(\mathrm{C}$ and E): $25 \mu \mathrm{m}$
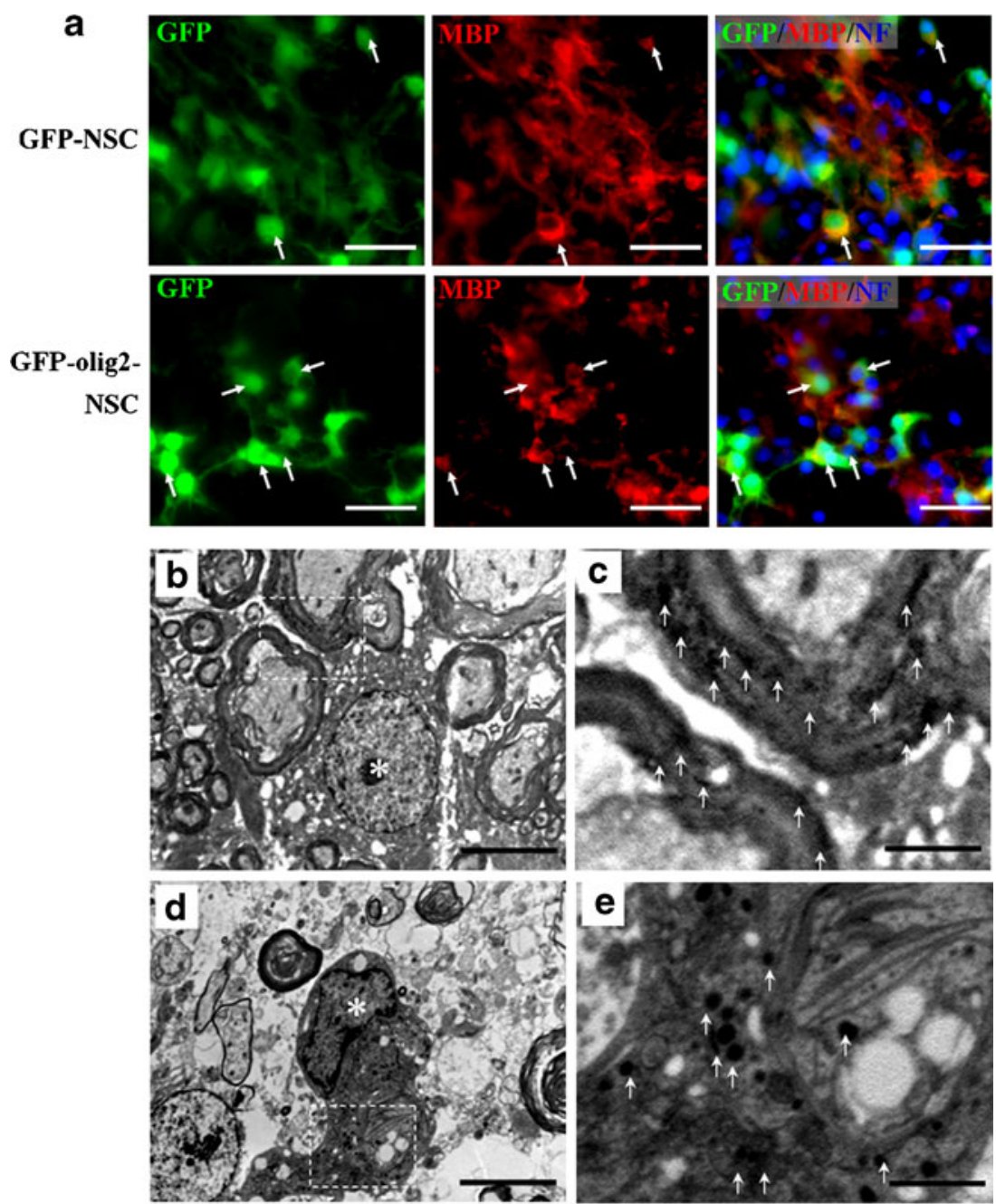

isolated from fetal and adult CNS, proliferate, and can be passaged and cryopreserved, thereby being a reliable source for cell therapy. However, transplanted NSCs mainly differentiate into astrocytes with very few $(<5 \%)$ OLs in injured spinal cord $[5,50-53]$. This may be attributed to the multipotency of NSCs and the unfavorable microenvironment for the OL differentiation in the injured spinal cord. Therefore, it is of great importance to direct differentiation of transplanted NSCs into OLs, and to improve the microenvironment of the injured spinal cords.

In the present study, we demonstrated that $>50 \%$ of Olig2-GFP-NSCs were differentiated into fully mature OLs in NSC differentiation medium. This result was consistent with recent reports that show overexpression of Olig2 transcription factor is sufficient to activate cellular machinery in NSCs, which promotes differentiation into OLs [27, 28, 54-56]. In addition, although Olig2-overexpressing NSCs differentiated into OLs in NSC differentiation medium, the cells maintained an undifferentiated state in growth medium containing EGF and bFGF. These results demonstrated that our Olig2-overexpressing NSCs can be maintained in vitro, and Olig2-overexpression may promote differentiation of transplanted NSCs into OLs.

To improve the microenvironment of the injured spinal cord, we used MBP-T-cell adoptive immunotherapy, which was based on "protective autoimmunity" [10-13] and our previous study [14]. Although the concept and safety of clinical therapies have been severely suspected [57-60], recent reports from ourselves and others have suggested that at least in the experimental allergic encephalomyelitis (EAE)-resistant SD rats, adoptive immunotherapy using MBP-T cells shows a neuroprotective effect on the injured spinal cord [14, 61, 62]. The protective effect of MBP-T cells may be due to their ability to release neurotrophic factors [63, 64], induce microglia to buffer toxic mediators (such as glutamate), and remove growth inhibitors (e.g., by phagocytosis of myelin) [65-69]. In this study, we demonstrated that MBP-T cells were mainly $\mathrm{CD}^{+} \mathrm{CD}^{+} \mathrm{T}$ cells $(>98 \%) .{ }^{3} \mathrm{H}-\mathrm{TdR}$ incorporation assays showed that MBP-T cells were reactive to MBP and extracts from rat 

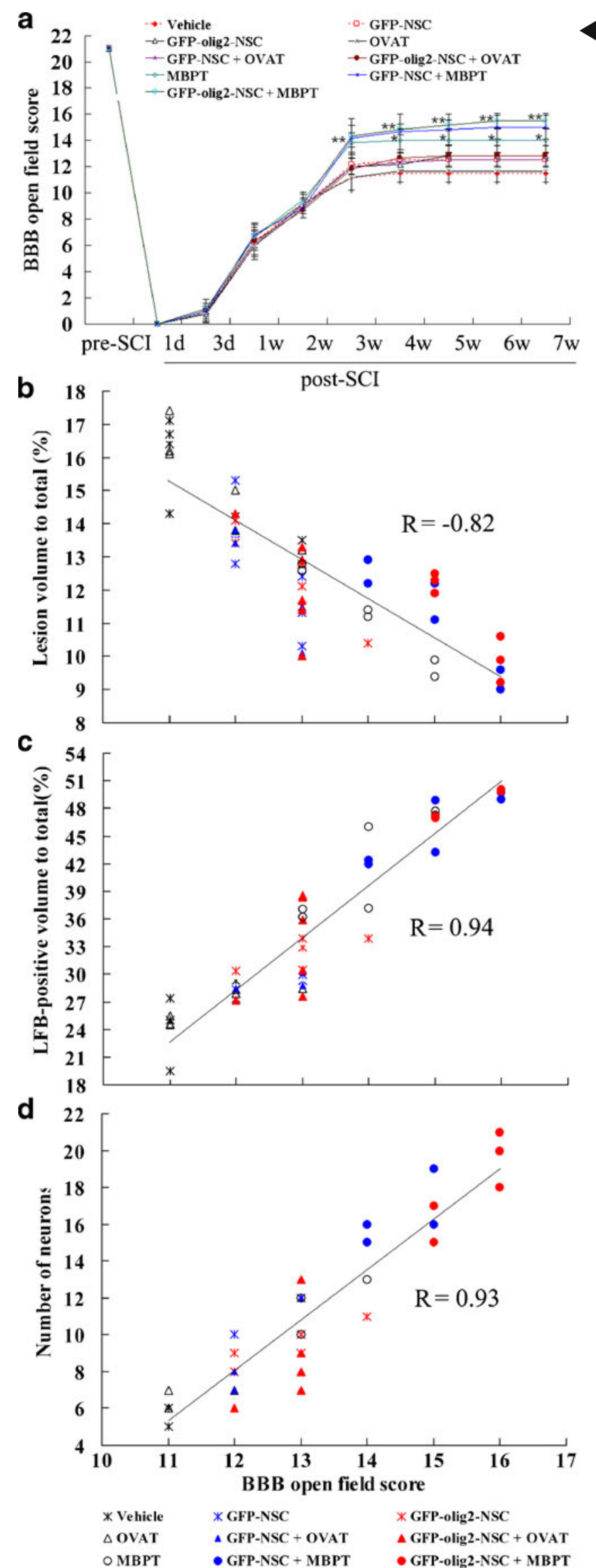

Fig. 13 Basso, Beattie, and Bresnahan (BBB) tests showing the effect of myelin basic protein-activated-T (MBP-T)-cell transfer and Olig2-overexpressing neural stem cell (NSC) transplantation on functional recovery following spinal cord injury (SCI). (A) BBB scores of the 9 groups were compared. Data are means \pm standard deviation $(\mathrm{n}=12 ; * p<0.05)$. (B-D) Correlational analysis of behavioral scores and total lesion (B), volume of residual myelin at the epicenter (C), and numbers of ventral horn (VH) motor neurons at 3$\mathrm{mm}$ rostral to the epicenter (D). Six rats in each group were analyzed $(\mathrm{n}=54) . \mathrm{GFP}=$ green fluorescent protein; $\mathrm{LFB}=$ luxol fast blue; OVAT $=$ ovalbumin-reactive activated $\mathrm{T}$

and guinea pig spinal cords. These results showed that MBP-T cells reacted with CNS antigens and may regulate the local immune response in the injured spinal cord.

Although MBP- and OVA-T cells showed a similar production pattern of cytokines and neurotrophins in vitro, only MBP-T cells infiltrated into the injured spinal cord for a long time period. These results also confirm that only activated T-cells migrate into the CNS, recognize CNS antigens, and remain in the CNS. Activated T-cells, but non-CNS-reactive, would rapidly migrate out of the CNS $[70,71]$. Therefore, the effects of passive immunization with MBP- and OVA-T cells on the local microenvironment were very different. In the injured spinal cord tissues, only IL-10 and IL-13 were highly expressed in the 3 MBP-T-cell-transferred groups, and high expression of neurotrophins, such as BDNF, NT-3, and NGF, was detected in all NSC (both GFP-NSCs and Olig2-GFPNSCs)-transplanted groups and MBP-T cell-transferred groups. Particularly in MBP-T cell and NSC combined groups, mRNA expression of these neurotrophins were significantly higher compared with those of other groups. Moreover, consistent with previous reports [72-75], proinflammatory cytokines, such as IFN- $\gamma$, IL- $1 \beta$, and TNF$\alpha$, were also highly expressed in the injured spinal cord. However, no differences were detected among groups. Neurotrophins produced by MBP-T cell and transplanted NSCs are well known to promote nerve cell growth and survival [76-78]. The role of inflammatory factors in SCI is complex. Anti-inflammatory cytokines, such as IL-10, IL-4, and IL-13, have been shown to be neuroprotective $[39,79-82]$. Pro-inflammatory cytokines, such as IFN- $\gamma$, IL-1 $\beta$ and TNF- $\alpha$, have been shown to be detrimental in CNS injury [72-75]. Therefore, we showed that MBP-Tcell passive immunization improves the local microenvironment by changing the balance between beneficial and detrimental cytokines. MBP-T-cell adoptive immunotherapy and NSC transplantation may have synergistic effects on the expression of some neurotrophins and antiinflammatory cytokines.

In addition to cytokines and neurotrophins, we also observed the effect of MBP-T-cell transfer on the local immune response of CNS macrophages, which includes 
resident microglia and/or macrophages derived from infiltrating monocytes. We examined the phenotypes of 2 distinct macrophage subsets, which are referred to as "classically-activated" pro-inflammatory (M1) and "alternatively-activated" anti-inflammatory (M2) cells, respectively [39]. Consistent with a report by Kigerl et al. [39], the M1 macrophage response was rapidly induced and then maintained in the injured spinal cord in all groups. In the control and OVA-T-cell-transferred groups, the M2 macrophage response was transient and overwhelmed by the M1 response, which is also similar to observations by Kigerl et al. [39]. However, in MBP-T-cell-transferred groups, the M2 macrophage response was maintained at a high level up to $28 \mathrm{dpi}$ (the longest time period evaluated in this study). The ratio of the M1:M2 macrophages has significant implications in CNS repair. M1 macrophages are neurotoxic and M2 macrophages promote axonal regeneration after CNS injury [39, 83, 84]. Our results suggest that MBP-Tcell passive immunization promotes the differentiation of resident microglia and infiltrating blood monocytes toward an M2 macrophage phenotype. This effect may improve the local microenvironment to promote CNS repair.

Pro-inflammatory cytokines, such as IFN- $\gamma$ and TNF- $\alpha$, are important mediators in promoting the development of M1 macrophages [39, 85]. However, M2 macrophages form in the presence of anti-inflammatory cytokines, such as IL-4, IL-10, and IL-13 [39, 86-88]. In this study, although we detected high expression of pro-inflammatory cytokines in the injured spinal cord, no significant difference was found among groups. However, MBP-Tcell adoptive immunotherapy induced high expression of anti-inflammatory cytokines IL-13 and IL-10. Although IL4 expression was only detected at a basal level in all groups, IL-13 and IL-10 induced the development of M2 macrophages in MBP-T-cell-transferred groups.

Next, we observed the survival and differentiation of transplanted NSCs. We found that MBP-T-cell adoptive immunotherapy resulted in a dramatic increase in the numbers of transplanted NSCs. This effect may be due to the production of neurotrophins and anti-inflammatory cytokines, but the precise mechanisms require further study. OL differentiation of transplanted NSCs is vital for SCI treatment. It is of great significance to clarify whether Olig2-overexpression affects differentiation of transplanted NSCs. Similar to previous reports, Olig2-overexpressing NSCs effectively differentiated into OLs after transplantation into the injured spinal cord [28]. Using GFP/NFM/ MBP 3-color immunofluorescence and immuno-EM of GFP, we further determined that these OLs were derived from transplanted NSCs and formed myelin sheaths around axons.

Following SCI, regenerated myelin is mainly formed by SCs and OLs [40]. To clarify the cellular source of regenerated myelin, the remyelination was further quanti- fied using toluidine blue-stained semi-thin sections. We found that MBP-T-cell adoptive immunotherapy significantly increased the number of SC-remyelinated axons in the injured spinal cord, and the number of OL-remyelinated axons in animals that received both Olig2-GFP-NSC transplantation and MBP-T-cell adoptive immunotherapy significantly increased compared with that of all other groups. These results indicate that MBP-T-cell transfer may create a microenvironment that is conducive not only to survival and differentiation of transplanted NSCs into myelinated OLs, but also migration and myelination of SCs in the injured spinal cord.

To determine whether NSC transplantation and/or T-cell adoptive immunotherapy improve functional recovery after SCI, morphological and functional assays were performed. We found a significant decrease in spinal cord lesion volume in all MBP-T-cell-transferred groups and NSCtransplanted groups. Additionally, increases in spared myelin, myelinated axons, and neurons were found, compared with those of vehicle-treated and OVA-T-celltransferred groups. This histological improvement correlated well with an increase in behavioral recovery. It is worth emphasizing that although Olig2-overexpression enhanced OL differentiation and myelination, histological and behavioral improvement showed no significant difference between Olig2-overexpressing NSC transplantation combined with MBP-T transfer and NSC transplantation combined with MBP-T transfer. In a recent study, Hwang et al. [28] reported that Olig2-overexpressing NSCs significantly increase the extent of myelination and improve locomotor recovery compared with that of NSCs. The reason why no significant differences were detected between the 2 cell types in our experiment may be due to the MBP-T-cell adoptive immunotherapy. Neuroprotection of MBP-T cells may surpass the contribution of OL differentiation and myelination. In this case, whether Olig2 overexpression is necessary for neuroprotection or how to improve the contribution of Olig2-overexpressing NSCs in SCI repair remains an important issue.

\section{Conclusion}

In conclusion, our study shows that MBP-T cells produce neurotrophic factors, improve the SCI microenvironment and are neuroprotective to residual myelin and neurons. MBP-T cells combined with NSCs or Olig2-overexpressing NSCs show a synergistic effect on histological and behavioral improvement after traumatic SCI. Olig2 overexpression promotes the differentiation of NSCs into mature OLs in the injured spinal cord, but there is no significant additive effect on functional recovery. 
Acknowledgments This study was supported by grants from the National Natural Science Foundation of China (No. 81071268, 81171465), the Science and Technological Fund of Anhui Province for Outstanding Youth (No. 10040606Y13), the Natural Science Research Program of Education Bureau of Anhui Province (No. KJ2010B109), and the Key Project of the Chinese Ministry of Education (No. 210103).

Required Author Forms Disclosure forms provided by the authors are available with the online version of this article.

\section{References}

1. Nandoe Tewarie RS, Hurtado A, Bartels RH, Grotenhuis A, Oudega M. Stem cell-based therapies for spinal cord injury. J Spinal Cord Med 2009;32:105-114.

2. Karimi-Abdolrezaee S, Eftekharpour E, Wang J, Morshead CM, Fehlings MG. Delayed transplantation of adult neural precursor cells promotes remyelination and functional neurological recovery after spinal cord injury. J Neurosci 2006;26:3377-3389.

3. Thuret S, Moon LD, Gage FH. Therapeutic interventions after spinal cord injury. Nat Rev Neurosci 2006;7:628-643.

4. $\mathrm{Xu} \mathrm{XM}$, Onifer SM. Transplantation-mediated strategies to promote axonal regeneration following spinal cord injury. Respir Physiol Neurobiol 2009;169:171-182.

5. Cao QL, Zhang YP, Howard RM, Walters WM, Tsoulfas P, Whittemore SR. Pluripotent stem cells engrafted into the normal or lesioned adult rat spinal cord are restricted to a glial lineage. Exp Neurol 2001;167:48-58.

6. Ricci-Vitiani L, Casalbore P, Petrucci G, et al. Influence of local environment on the differentiation of neural stem cells engrafted onto the injured spinal cord. Neurol Res 2006;28:488-492.

7. Blakemore WF, Gilson JM, Crang AJ. The presence of astrocytes in areas of demyelination influences remyelination following transplantation of oligodendrocyte progenitors. Exp Neurol 2003;184:955-963.

8. Butovsky O, Hauben E, Schwartz M. Morphological aspects of spinal cord autoimmune neuroprotection: colocalization of $\mathrm{T}$ cells with B7-2 (CD86) and prevention of cyst formation. Faseb J 2001;15:1065-1067.

9. Kipnis J, Mizrahi T, Hauben E, Shaked I, Shevach E, Schwartz M. Neuroprotective autoimmunity: naturally occurring CD4+CD25+ regulatory $\mathrm{T}$ cells suppress the ability to withstand injury to the central nervous system. Proc Natl Acad Sci U S A 2002;99:15620-15625.

10. Schwartz M. Harnessing the immune system for neuroprotection: therapeutic vaccines for acute and chronic neurodegenerative disorders. Cell Mol Neurobiol 2001;21:617-627.

11. Schwartz M. Protective autoimmunity as a T-cell response to central nervous system trauma: prospects for therapeutic vaccines. Prog Neurobiol 2001;65:489-496.

12. Schwartz M, Kipnis J. Protective autoimmunity: regulation and prospects for vaccination after brain and spinal cord injuries. Trends Mol Med 2001;7:252-258.

13. Yoles E, Hauben E, Palgi O, et al. Protective autoimmunity is a physiological response to CNS trauma. J Neurosci 2001;21:37403748 .

14. Lu HZ, Xu L, Zou J, et al. Effects of autoimmunity on recovery of function in adult rats following spinal cord injury. Brain Behav Immun 2008;22:1217-1230

15. Ziv Y, Avidan H, Pluchino S, Martino G, Schwartz M. Synergy between immune cells and adult neural stem/progenitor cells promotes functional recovery from spinal cord injury. Proc Natl Acad Sci U S A 2006;103:13174-13179.
16. Cooke MJ, Zahir T, Phillips SR, et al. Neural differentiation regulated by biomimetic surfaces presenting motifs of extracellular matrix proteins. J Biomed Mater Res A 2010;93:824-832.

17. Lu HZ, Wang YX, Li Y, Fu SL, Hang Q, Lu PH. Proliferation and differentiation of oligodendrocyte progenitor cells induced from rat embryonic neural precursor cells followed by flow cytometry. Cytometry A 2008;73:754-760.

18. Lu HZ, Wang YX, Zou J, et al. Differentiation of neural precursor cellderived oligodendrocyte progenitor cells following transplantation into normal and injured spinal cords. Differentiation 2010;80:228-240.

19. Mitsuhashi T, Takahashi T. Genetic regulation of proliferation/ differentiation characteristics of neural progenitor cells in the developing neocortex. Brain Dev 2009;31:553-557.

20. Kwon BK, Tetzlaff W, Grauer JN, Beiner J, Vaccaro AR. Pathophysiology and pharmacologic treatment of acute spinal cord injury. Spine J 2004;4:451-464.

21. Rowland JW, Hawryluk GW, Kwon B, Fehlings MG. Current status of acute spinal cord injury pathophysiology and emerging therapies: promise on the horizon. Neurosurg Focus 2008;25:E2.

22. Sheerin F. Spinal cord injury: causation and pathophysiology. Emerg Nurse 2005;12:29-38.

23. Cheng X, Wang Y, He Q, Qiu M, Whittemore SR, Cao Q. Bone morphogenetic protein signaling and olig $1 / 2$ interact to regulate the differentiation and maturation of adult oligodendrocyte precursor cells. Stem Cells 2007;25:3204-3214.

24. Takebayashi H, Nabeshima Y, Yoshida S, Chisaka O, Ikenaka K, Nabeshima Y. The basic helix-loop-helix factor olig2 is essential for the development of motoneuron and oligodendrocyte lineages. Curr Biol 2002;12:1157-1163.

25. Zhou Q, Anderson DJ. The bHLH transcription factors OLIG2 and OLIG1 couple neuronal and glial subtype specification. Cell 2002;109:61-73.

26. Balasubramaniyan V, Timmer N, Kust B, Boddeke E, Copray S. Transient expression of Olig1 initiates the differentiation of neural stem cells into oligodendrocyte progenitor cells. Stem Cells 2004;22:878-882.

27. Copray S, Balasubramaniyan V, Levenga J, de Bruijn J, Liem R, Boddeke E. Olig2 overexpression induces the in vitro differentiation of neural stem cells into mature oligodendrocytes. Stem Cells 2006;24:1001-1010.

28. Hwang DH, Kim BG, Kim EJ, et al. Transplantation of human neural stem cells transduced with Olig2 transcription factor improves locomotor recovery and enhances myelination in the white matter of rat spinal cord following contusive injury. BMC Neurosci 2009;10:117.

29. Fu SL, Ma ZW, Yin L, Iannotti C, Lu PH, Xu XM. Region-specific growth properties and trophic requirements of brain- and spinal cordderived rat embryonic neural precursor cells. Neuroscience 2005; 135:851-862.

30. He Y, Zhang J, Mi Z, Robbins P, Falo LD Jr. Immunization with lentiviral vector-transduced dendritic cells induces strong and long-lasting $\mathrm{T}$ cell responses and therapeutic immunity. J Immunol 2005; 174:3808-3817.

31. Moalem G, Leibowitz-Amit R, Yoles E, Mor F, Cohen IR, Schwartz M. Autoimmune T cells protect neurons from secondary degeneration after central nervous system axotomy. Nat Med 1999;5:49-55.

32. Gu WL, Fu SL, Wang YX, et al. Expression and regulation of versican in neural precursor cells and their lineages. Acta Pharmacol Sin 2007;28:1519-1530.

33. Pfaffl MW. A new mathematical model for relative quantification in real-time RT-PCR. Nucleic Acids Res 2001;29:e45.

34. Beck KD, Nguyen HX, Galvan MD, Salazar DL, Woodruff TM, Anderson AJ. Quantitative analysis of cellular inflammation after traumatic spinal cord injury: evidence for a multiphasic inflammatory 
response in the acute to chronic environment. Brain 2010;133:433447.

35. Cao Q, Xu XM, Devries WH et al. Functional recovery in traumatic spinal cord injury after transplantation of multineurotrophinexpressing glial-restricted precursor cells. J Neurosci 2005;25:69476957.

36. Basso DM, Beattie MS, Bresnahan JC. A sensitive and reliable locomotor rating scale for open field testing in rats. J Neurotrauma 1995; 12:1-21.

37. Basso DM, Beattie MS, Bresnahan JC, et al. MASCIS evaluation of open field locomotor scores: effects of experience and teamwork on reliability. Multicenter Animal Spinal Cord Injury Study. J Neurotrauma 1996;13:343-359.

38. Lendahl U, Zimmerman LB, McKay RD. CNS stem cells express a new class of intermediate filament protein. Cell 1990;60:585595.

39. Kigerl KA, Gensel JC, Ankeny DP, Alexander JK, Donnelly DJ, Popovich PG. Identification of two distinct macrophage subsets with divergent effects causing either neurotoxicity or regeneration in the injured mouse spinal cord. J Neurosci 2009;29:1343513444.

40. Cao Q, He Q, Wang Y, et al. Transplantation of ciliary neurotrophic factor-expressing adult oligodendrocyte precursor cells promotes remyelination and functional recovery after spinal cord injury. J Neurosci 2010;30:2989-3001.

41. Gilson JM, Blakemore WF. Schwann cell remyelination is not replaced by oligodendrocyte remyelination following ethidium bromide induced demyelination. Neuroreport 2002;13:12051208.

42. Hildebrand C, Hahn R. Relation between myelin sheath thickness and axon size in spinal cord white matter of some vertebrate species. J Neurol Sci 1978;38:421-434.

43. McDonald JW. Repairing the damaged spinal cord. Sci Am 1999;281:64-73.

44. McDonald JW. Repairing the damaged spinal cord: from stem cells to activity-based restoration therapies. Clin Neurosurg 2004;51:207-227.

45. McDonald JW, Howard MJ. Repairing the damaged spinal cord: a summary of our early success with embryonic stem cell transplantation and remyelination. Prog Brain Res 2002;137:299-309.

46. Coutts M, Keirstead HS. Stem cells for the treatment of spinal cord injury. Exp Neurol 2008;209:368-377.

47. Enzmann GU, Benton RL, Talbott JF, Cao Q, Whittemore SR. Functional considerations of stem cell transplantation therapy for spinal cord repair. J Neurotrauma 2006;23:479-495.

48. Kulbatski I, Mothe AJ, Parr AM, et al. Glial precursor cell transplantation therapy for neurotrauma and multiple sclerosis. Prog Histochem Cytochem 2008;43:123-176.

49. Louro J, Pearse DD. Stem and progenitor cell therapies: recent progress for spinal cord injury repair. Neurol Res 2008;30:5-16.

50. Chow SY, Moul J, Tobias CA, et al. Characterization and intraspinal grafting of EGF/bFGF-dependent neurospheres derived from embryonic rat spinal cord. Brain Res 2000;874:87-106.

51. Hofstetter CP, Holmstrom NA, Lilja JA, et al. Allodynia limits the usefulness of intraspinal neural stem cell grafts; directed differentiation improves outcome. Nat Neurosci 2005;8:346-353.

52. Shihabuddin LS, Horner PJ, Ray J, Gage FH. Adult spinal cord stem cells generate neurons after transplantation in the adult dentate gyrus. J Neurosci 2000;20:8727-8735.

53. Wu S, Suzuki Y, Noda T, et al. Immunohistochemical and electron microscopic study of invasion and differentiation in spinal cord lesion of neural stem cells grafted through cerebrospinal fluid in rat. J Neurosci Res 2002;69:940-945.

54. Ahn SM, Byun K, Kim D et al. Olig2-induced neural stem cell differentiation involves downregulation of Wnt signaling and induction of Dickkopf-1 expression. PLoS One 2008;3:e3917.
55. Islam MS, Tatsumi K, Okuda $\mathrm{H}$, Shiosaka S, Wanaka A. Olig2-expressing progenitor cells preferentially differentiate into oligodendrocytes in cuprizone-induced demyelinated lesions. Neurochem Int 2009;54:192-198.

56. Liu Z, Hu X, Cai J, et al. Induction of oligodendrocyte differentiation by Olig2 and Sox10: evidence for reciprocal interactions and dosage-dependent mechanisms. Dev Biol 2007;302:683-693.

57. Ankeny DP, Popovich PG. Central nervous system and non-central nervous system antigen vaccines exacerbate neuropathology caused by nerve injury. Eur J Neurosci 2007;25:2053-2064.

58. Jones TB, Ankeny DP, Guan Z, et al. Passive or active immunization with myelin basic protein impairs neurological function and exacerbates neuropathology after spinal cord injury in rats. J Neurosci 2004;24:3752-3761.

59. Jones TB, Basso DM, Sodhi A, et al. Pathological CNS autoimmune disease triggered by traumatic spinal cord injury: implications for autoimmune vaccine therapy. J Neurosci 2002;22:2690-2700.

60. Popovich PG, Jones TB. Manipulating neuroinflammatory reactions in the injured spinal cord: back to basics. Trends Pharmacol Sci 2003;24:13-17.

61. Hauben E, Butovsky O, Nevo U, et al. Passive or active immunization with myelin basic protein promotes recovery from spinal cord contusion. J Neurosci 2000;20:6421-6430.

62. Kipnis J, Yoles E, Schori H, Hauben E, Shaked I, Schwartz M. Neuronal survival after CNS insult is determined by a genetically encoded autoimmune response. J Neurosci 2001;21:4564-4571.

63. Barouch R, Schwartz M. Autoreactive T cells induce neurotrophin production by immune and neural cells in injured rat optic nerve: implications for protective autoimmunity. Faseb J 2002;16:13041306.

64. Moalem G, Gdalyahu A, Shani Y, et al. Production of neurotrophins by activated T cells: implications for neuroprotective autoimmunity. $\mathrm{J}$ Autoimmun 2000;15:331-345.

65. Avidan H, Kipnis J, Butovsky O, Caspi RR, Schwartz M. Vaccination with autoantigen protects against aggregated betaamyloid and glutamate toxicity by controlling microglia: effect of CD4+CD25+ T cells. Eur J Immunol 2004;34:3434-3445.

66. Butovsky O, Bukshpan S, Kunis G, Jung S, Schwartz M. Microglia can be induced by IFN-gamma or IL-4 to express neural or dendritic-like markers. Mol Cell Neurosci 2007;35:490 500 .

67. Schori H, Robenshtok E, Schwartz M, Hourvitz A. Postintoxication vaccination for protection of neurons against the toxicity of nerve agents. Toxicol Sci 2005;87:163-168.

68. Schwartz M. Macrophages and microglia in central nervous system injury: are they helpful or harmful? J Cereb Blood Flow Metab 2003;23:385-394.

69. Shaked I, Tchoresh D, Gersner R, et al. Protective autoimmunity: interferon-gamma enables microglia to remove glutamate without evoking inflammatory mediators. J Neurochem 2005;92:9971009.

70. Hickey WF, Hsu BL, Kimura H. T-lymphocyte entry into the central nervous system. J Neurosci Res 1991;28:254-260.

71. Jones TB, Hart RP, Popovich PG. Molecular control of physiological and pathological T-cell recruitment after mouse spinal cord injury. J Neurosci 2005;25:6576-6583.

72. Bartholdi D, Schwab ME. Expression of pro-inflammatory cytokine and chemokine mRNA upon experimental spinal cord injury in mouse: an in situ hybridization study. Eur J Neurosci 1997;9:1422-1438.

73. Nakamura M, Houghtling RA, MacArthur L, Bayer BM, Bregman BS. Differences in cytokine gene expression profile between acute and secondary injury in adult rat spinal cord. Exp Neurol 2003; 184:313-325. 
74. Wu KL, Chan SH, Chao YM, Chan JY. Expression of proinflammatory cytokine and caspase genes promotes neuronal apoptosis in pontine reticular formation after spinal cord transection. Neurobiol Dis 2003;14:19-31.

75. Yang L, Jones NR, Blumbergs PC, et al. Severity-dependent expression of pro-inflammatory cytokines in traumatic spinal cord injury in the rat. J Clin Neurosci 2005;12:276-284.

76. Chu TH, Wu W. Neurotrophic factor treatment after spinal root avulsion injury. Cent Nerv Syst Agents Med Chem 2009;9:40-55.

77. Mocchetti I, Wrathall JR. Neurotrophic factors in central nervous system trauma. J Neurotrauma 1995;12:853-870.

78. Sharma HS. Neurotrophic factors in combination: a possible new therapeutic strategy to influence pathophysiology of spinal cord injury and repair mechanisms. Curr Pharm Des 2007;13:1841-1874.

79. Bethea JR. Spinal cord injury-induced inflammation: a dual-edged sword. Prog Brain Res 2000;128:33-42.

80. Offner H, Subramanian S, Wang C, et al. Treatment of passive experimental autoimmune encephalomyelitis in SJL mice with a recombinant TCR ligand induces IL-13 and prevents axonal injury. J Immunol 2005;175:4103-4111.

81. Schroeter M, Jander S. T-cell cytokines in injury-induced neural damage and repair. Neuromolecular Med 2005;7:183-195.
82. Stoll G, Jander S, Schroeter M. Cytokines in CNS disorders: neurotoxicity versus neuroprotection. J Neural Transm Suppl 2000;59:81-89.

83. Goerdt S, Orfanos CE. Other functions, other genes: alternative activation of antigen-presenting cells. Immunity 1999;10:137-142.

84. Mikita J, Dubourdieu-Cassagno N, Deloire MS, et al. Altered M1/ M2 activation patterns of monocytes in severe relapsing experimental rat model of multiple sclerosis. Amelioration of clinical status by M2 activated monocyte administration. Mult Scler $\mathrm{xxxx} ; 17: 2-15$.

85. Mosser DM, Edwards JP. Exploring the full spectrum of macrophage activation. Nat Rev Immunol 2008;8:958-969.

86. Bethea JR, Nagashima H, Acosta MC, et al. Systemically administered interleukin-10 reduces tumor necrosis factor-alpha production and significantly improves functional recovery following traumatic spinal cord injury in rats. J Neurotrauma 1999;16:851-863.

87. Martinez FO, Sica A, Mantovani A, Locati M. Macrophage activation and polarization. Front Biosci 2008;13:453-461.

88. Sica A, Schioppa T, Mantovani A, Allavena P. Tumour-associated macrophages are a distinct M2 polarised population promoting tumour progression: potential targets of anti-cancer therapy. Eur J Cancer 2006;42:717-727. 